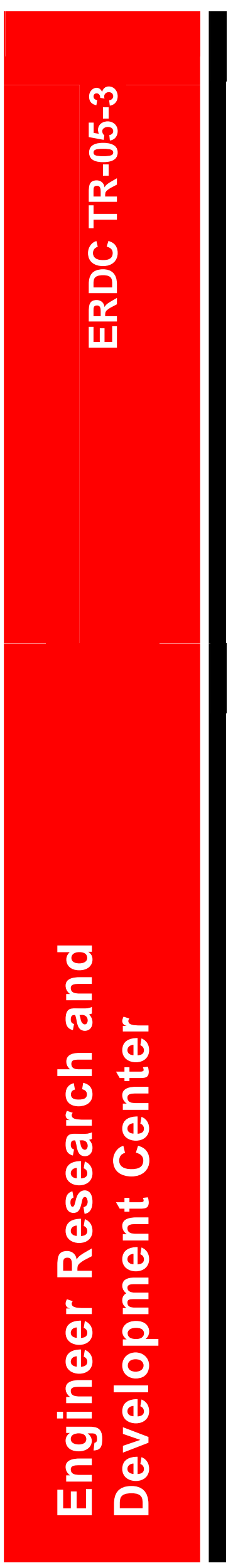

Methodology for Risk Analysis of Dam Gates and Associated Operating Equipment Using Fault Tree Analysis

Robert C. Patev, Chandra Putcha, and Stuart D. Foltz

May 2005 


\title{
Methodology for Risk Analysis of Dam Gates and Associated Operating Equipment Using Fault Tree Analysis
}

\author{
Robert C. Patev \\ New England District \\ U.S. Army Corps of Engineers \\ 696 Virginia Road \\ Concord , MA 01742-2751 \\ Chandra Putcha \\ Department of Civil and Environmental Engineering \\ California State University \\ Fullerton, CA 92834 \\ Stuart D. Foltz \\ U.S. Army Engineer Research and Development Center \\ Construction Engineering Research Laboratory \\ PO Box 9005 \\ Champaign, IL 61826-9005
}

Final Report

Approved for public release; distribution is unlimited.

$\begin{array}{ll}\text { Prepared for } & \text { U.S. Army Corps of Engineers } \\ \text { Washington, DC 20314-1000 }\end{array}$

Under

Work Unit RADS 33262 
ABSTRACT: With limited maintenance dedicated to aging dam spillway gate structures, there is an increased risk of gate inoperability and corresponding dam failure due to malfunction or inadequate design. This report summarizes research on methodologies to assist in quantifying risks related to dam gates and associated operating equipment, and how those risks relate to overall spillway failure risk. The objective of the research was to demonstrate how fault tree analytical methods may be applied to improve the quality of dam gate risk analysis.

Two different methods of prescreening analysis are presented and evaluated. The first uses probabilities for more events, defined more precisely than in standard practice, and adds criticality ranking; the second uses more traditional estimation of failure probabilities in conjunction with subsystem importance-ranking factors to estimate overall gate system failure probability. Both methods can be linked qualitatively with the Lafitte risk method through event costs and consequences to determine the overall risk for a dam spillway system.

Enhancement of the two demonstrated methods would require a direct application of the methods to an existing dam gate system. Also, additional research would be necessary to better determine the risk consequence factor, $\alpha$, used in the Lafitte equation for calculating overall risk.

DISCLAIMER: The contents of this report are not to be used for advertising, publication, or promotional purposes. Citation of trade names does not constitute an official endorsement or approval of the use of such commercial products. All product names and trademarks cited are the property of their respective owners. The findings of this report are not to be construed as an official Department of the Army position unless so designated by other authorized documents.

DESTROY THIS REPORT WHEN NO LONGER NEEDED. DO NOT RETURN IT TO THE ORIGINATOR. 


\section{Contents}

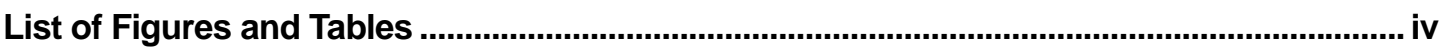

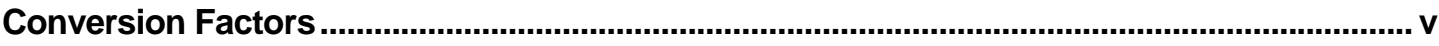

Preface

1 Introduction

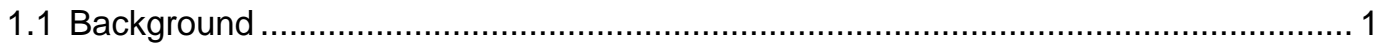

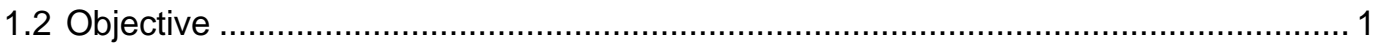

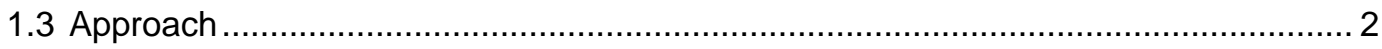

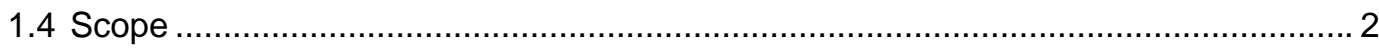

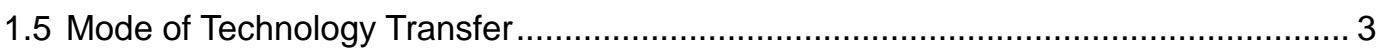

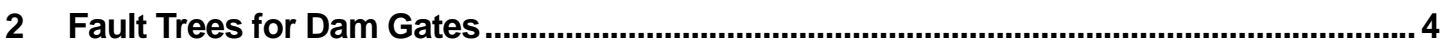

3 Prospective Methods for Prescreening Dam Gate Components.................................... 12

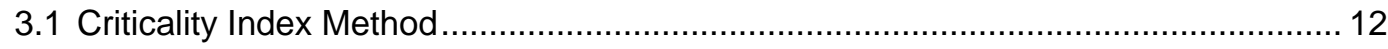

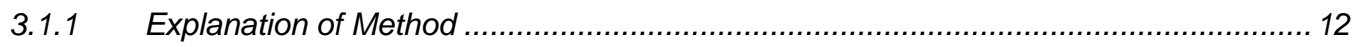

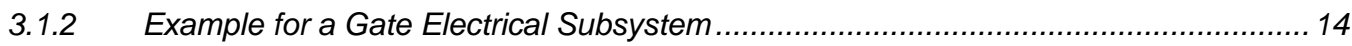

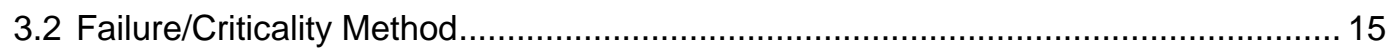

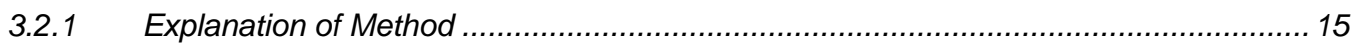

3.2.2 Example of Probability of Failure and Mission Criticality Calculations..........................19

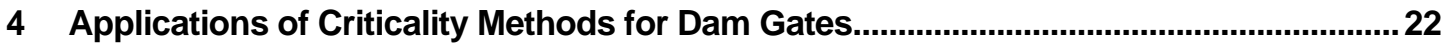

4.1 Criticality Index for Comparison of Gate Subsystems and Fault Trees .................... 22

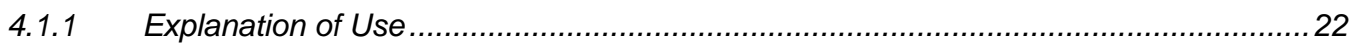

4.1.2 Example of Calculation for Electrical Subsystem of Dam Gates ................................2 24

4.2 Failure Probability Method for Comparison of Gate Subsystems and Fault

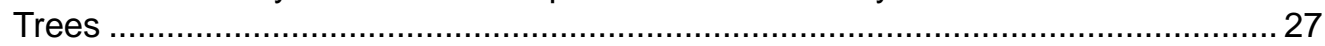

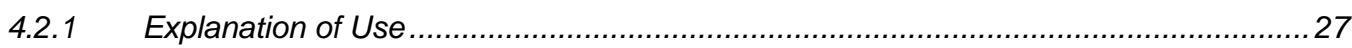

4.2.2 Example of Calculation for Electrical Subsystem ................................................ 28

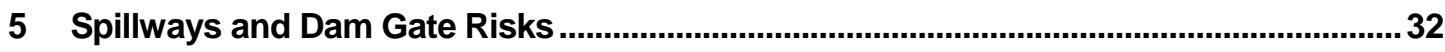

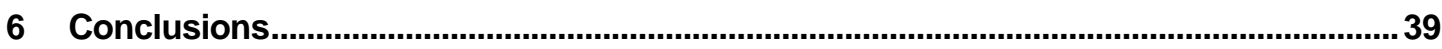

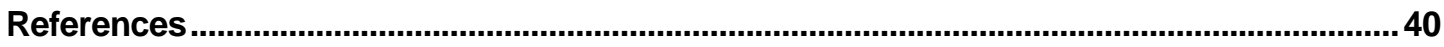




\section{List of Figures and Tables}

\section{Figures}

Figure 1. Typical symbols used in fault tree analysis. ............................................... 4

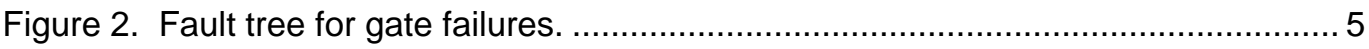

Figure 3. Fault tree for gate structural breakdown. .................................................... 6

Figure 4. Fault tree for gate mechanical breakdown. .................................................... 6

Figure 5. Fault tree for gate electrical breakdown..................................................... 7

Figure 6. Fault tree for gate operational breakdown. …............................................. 7

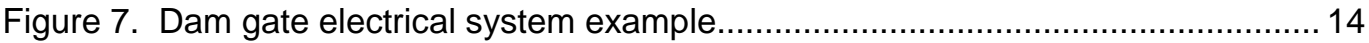

Figure 8. Example of ranking based on functional and hardware criticality. ................. 20

Figure 9. Classification of failure modes for electrical system example......................... 21

Figure 10. Nonlinear relationship between risk consequence factor and probability

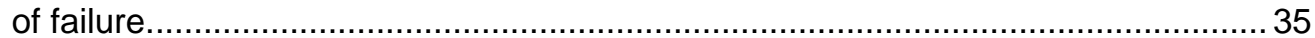

Figure 11. Baseline condition - no rehabilitation.................................................. 36

Figure 12. Alternative 1 - rehabilitation of all components in Year 25...........................36

Figure 13. Alternative 2 - rehabilitation of mechanical and electrical components in Year 15 and structural components in Year 30................................................... 37

Figure 14. Summary of risk-reduction measures for spillway system......................... 37

\section{Tables}

Table 1. Example causes of failure events for fault trees shown in Figures $2-6 \ldots \ldots \ldots \ldots . . .8$

Table 2. Example of criticality index values for a turbine generator. .............................. 15

Table 3. Hardware criticality (Boeing 1998) ................................................................ 16

Table 4. Functional criticality (Boeing 1998)............................................................. 16

Table 5. Combined criticality of the failure mode (Boeing 1998) ................................ 17

Table 6. Classification of failure modes (Boeing 1998). .......................................... 18

Table 7. Example criticality index calculations for turbine generator. ............................ 20

Table 8. Hypothetical example of risk from gate or foundation failure for a spillway system 


\section{Conversion Factors}

Non-SI* units of measure used in this report can be converted to SI units as follows:

\begin{tabular}{|c|c|c|}
\hline Multiply & By & To Obtain \\
\hline acres & $4,046.873$ & square meters \\
\hline cubic feet & 0.02831685 & cubic meters \\
\hline cubic inches & 0.00001638706 & cubic meters \\
\hline degrees (angle) & 0.01745329 & radians \\
\hline degrees Fahrenheit & $(5 / 9) \times\left({ }^{\circ} \mathrm{F}-32\right)$ & degrees Celsius \\
\hline degrees Fahrenheit & $(5 / 9) \times\left({ }^{\circ} \mathrm{F}-32\right)+273.15$ & kelvins \\
\hline feet & 0.3048 & meters \\
\hline gallons (U.S. liquid) & 0.003785412 & cubic meters \\
\hline horsepower (550 ft-lb force per second) & 745.6999 & watts \\
\hline inches & 0.0254 & meters \\
\hline kips per square foot & 47.88026 & kilopascals \\
\hline kips per square inch & 6.894757 & megapascals \\
\hline miles (U.S. statute) & 1.609347 & kilometers \\
\hline pounds (force) & 4.448222 & newtons \\
\hline pounds (force) per square inch & 0.006894757 & megapascals \\
\hline pounds (mass) & 0.4535924 & kilograms \\
\hline square feet & 0.09290304 & square meters \\
\hline square miles & $2,589,998$ & square meters \\
\hline tons (force) & $8,896.443$ & newtons \\
\hline tons $(2,000$ pounds, mass $)$ & 907.1847 & kilograms \\
\hline yards & 0.9144 & meters \\
\hline
\end{tabular}

\footnotetext{
*Système International d'Unités (International System of Measurement), i.e., the metric system.
} 


\section{Preface}

The work described in this report was authorized by Headquarters, U.S. Army Corps of Engineers (HQUSACE), as part of the Risk Analysis for Dam Safety (RADS) Research and Development Program. The study was conducted under RADS Work Unit 33262, "Probability of Failure of Gates, Equipment, and Warning Systems." Mr. Robert C. Patev, formerly of U.S. Army Engineer Research and Development Center (ERDC), and Stuart Foltz (ERDC-CERL) were the coprincipal investigators for this research and Mr. Joseph A. Padula, ERDC, Information Technology Laboratory (ERDC ITL) is the current project manager.

Dr. Tony C. Liu was the RADS Coordinator at the Directorate of Research and Development, HQUSACE. Dr. Mary Ellen Hynes of the U.S. Army Engineer Research and Development Center (ERDC) was the Laboratory Manager for the RADS Program. Mr. H. Wayne Jones, ERDC, ITL, was the RADS Program Manager.

This research was performed and the report written by Mr. Robert C. Patev, New England District, U.S. Army Corps of Engineers, Dr. Chandra S. Putcha, Department of Civil and Environmental Engineering, California State University, Fullerton, and Mr. Stuart Foltz, Construction Engineering Research Laboratory (CERL), ERDC. The work was performed under the general supervision of Mr. H. Wayne Jones, Assistant Technical Director, ITL, Mr. Jeffery P. Holland, Director, ITL, and Dr. Alan Moore, CERL.

The authors would like to gratefully acknowledge the assistance of Corps employees David Van Dorpe, Joe Pletka, Phil Wagner, Curtis Bisgard, and Ronald Bockerman, who provided valuable expertise and assisted with site visits to Whittier Narrows and Gavins Point dams.

At the time of publication of this report COL James R. Weller, EN, was Commander and Executive Director of the ERDC and Dr. James R. Houston was the Director. 


\section{Introduction}

\subsection{Background}

Dams are an important part of the nation's public infrastructure, providing multiple benefits such as water supply, flood control, navigation, hydropower, recreation, and irrigation. However, with limited maintenance dedicated to aging gate structures at dam spillways, there is an increasing risk of potential dam failures due to gate inoperability, malfunction, or under-design. This report presents research directed toward the development of methodologies to assist in quantifying the risks for dam gates and associated operating equipment, and how these risks relate to overall spillway risk. The study represents an extension of previous research efforts documented in Putcha and Patev (2000).

The focus of this study was the development of analysis tools for risk assessment related to dam gates and associated operating equipment. Specifically, the applicability of detailed fault tree analysis to a dam spillway system is examined, with a concentration on the failure of the dam gates and operational subsystems. Two different methods of prescreening analysis are presented and evaluated. The first method uses probabilities for more events defined more precisely than in standard practice, and adds criticality analysis to rank each of the potential failure modes in a failure modes and effects analysis. The second method uses more traditional estimation of failure probabilities in conjunction with importance-ranking factors for the gate subsystems to estimate the probability of failure for the overall gate system. Detailed examples for gate subsystems are presented to show how the methodologies can be applied to dam gates. These methods can then be linked qualitatively with the Lafitte risk method through event costs and consequences to determine the associated overall risks for a dam spillway system.

\subsection{Objective}

The objective of this work was to demonstrate how fault tree analytical methods may be applied to improve the quality of dam gate risk analysis. 


\subsection{Approach}

The fault trees developed in this work effort were based on numerous consultations with design engineers at various Corps of Engineers dam facilities throughout the United States. Additionally, site visits were undertaken to Whittier Narrows Dam in the Los Angeles, CA, area; and the Gavins Point Dam in Yankton, SD. During the site visits, in-depth discussions were held with engineers familiar with those facilities. These engineers who participated in the development of the fault trees were multidisciplinary, and included operations and dam safety personnel. Results from a literature review of the Lafitte riskconsequence factor (Lafitte 1993, 1996) are also discussed.

\subsection{Scope}

The scope of the research reported here was limited to the risk analysis of dam gates and associated operating equipment, but not to an entire dam spillway system. In order for any dam spillway system risk analysis method to be effective, it is critical to have a valid data set on the failure rate of dam gate components, or at least methods for the timely acquisition of such data. Without better data, the methods proposed in this report, and any other risk-based methods, will lack the accuracy necessary to provide useful quantitative measures of risk. Systematic collection of data on the performance of gate components and all other critical components of the civil works inventory ${ }^{*}$ is essential to the success of an overall risk management program. Besides basic failure rate data for civil works applications, there are at least two other related data points that must be considered: maintenance history / condition and failure mode. Most failure rate databases include little or no consideration of component maintenance history and condition even though these obviously have a substantial impact on the equipment failure rate. Also, and specifically with respect to this report, some risk assessment methods presented here require some detailed information on the modes of failure for each component. This type of data is important because, for example, the impact of a locked brake is quite different from the consequences of a brake that will not hold.

\footnotetext{
* Such data are currently collected only for hydropower equipment. Rock Island District has had some limited success collecting data on electrical and mechanical gate equipment, which is available for inspection at http://www.mvr.usace.army.mil/failuredata/default.asp.
} 


\subsection{Mode of Technology Transfer}

The findings of this study demonstrate how fault tree methodologies could be incorporated in an Engineer Technical Letter (ETL) on dam gate risk analysis. 


\section{Fault Trees for Dam Gates}

Fault trees are one of the most important and simplest methods that can be used to help in the risk assessment of dam gates. These gate systems are often quite complex and detailed, with various types of structural, mechanical, and electrical equipment. Fault trees can provide a consistent framework on which an engineer can base a risk analysis.

Fault trees use different symbols to define both the inherent redundancy and operation of the gates and its subsystems. The typical symbols are shown in Figure 1. Triangles represent connection branches that fold in the events up to the top layer. Squares or rectangles represent a failure event or component. The 'inverted horseshoe' shape is an OR gate, which requires either sub-event or condition for the system to fail. AND gates are represented by a "railroad tunnel" shape and require all sub-events to occur. Circles indicate a basic or bottom level branch, which may be defined by many failure modes.

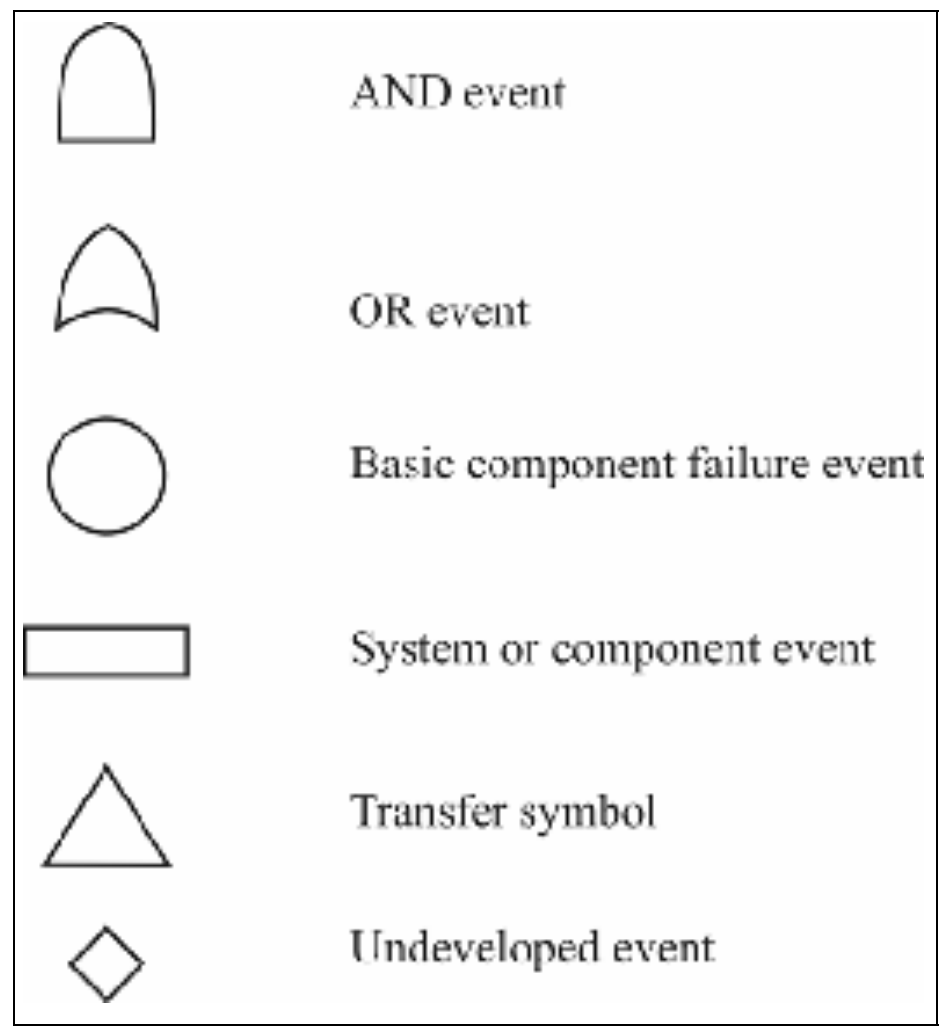

Figure 1. Typical symbols used in fault tree analysis. 
A simplified fault tree for dam gates and associated operating equipment is shown in Figure 2. The top event relates as to whether the gate fails in the open or closed position. The triangle at the top of Figure 2 relates to how the gate system that contains structural, electrical, and mechanical equipment contributes to the overall spillway risk. The overall spillway risk is not included in this fault tree but is discussed to some extent in Chapter 6. The goal of these fault trees is to define a highly detailed (i.e., "bushy") representation of the fault environment so that the user can rapidly eliminate or accept branches on the basis of prescreening and background knowledge of the specific dam project.

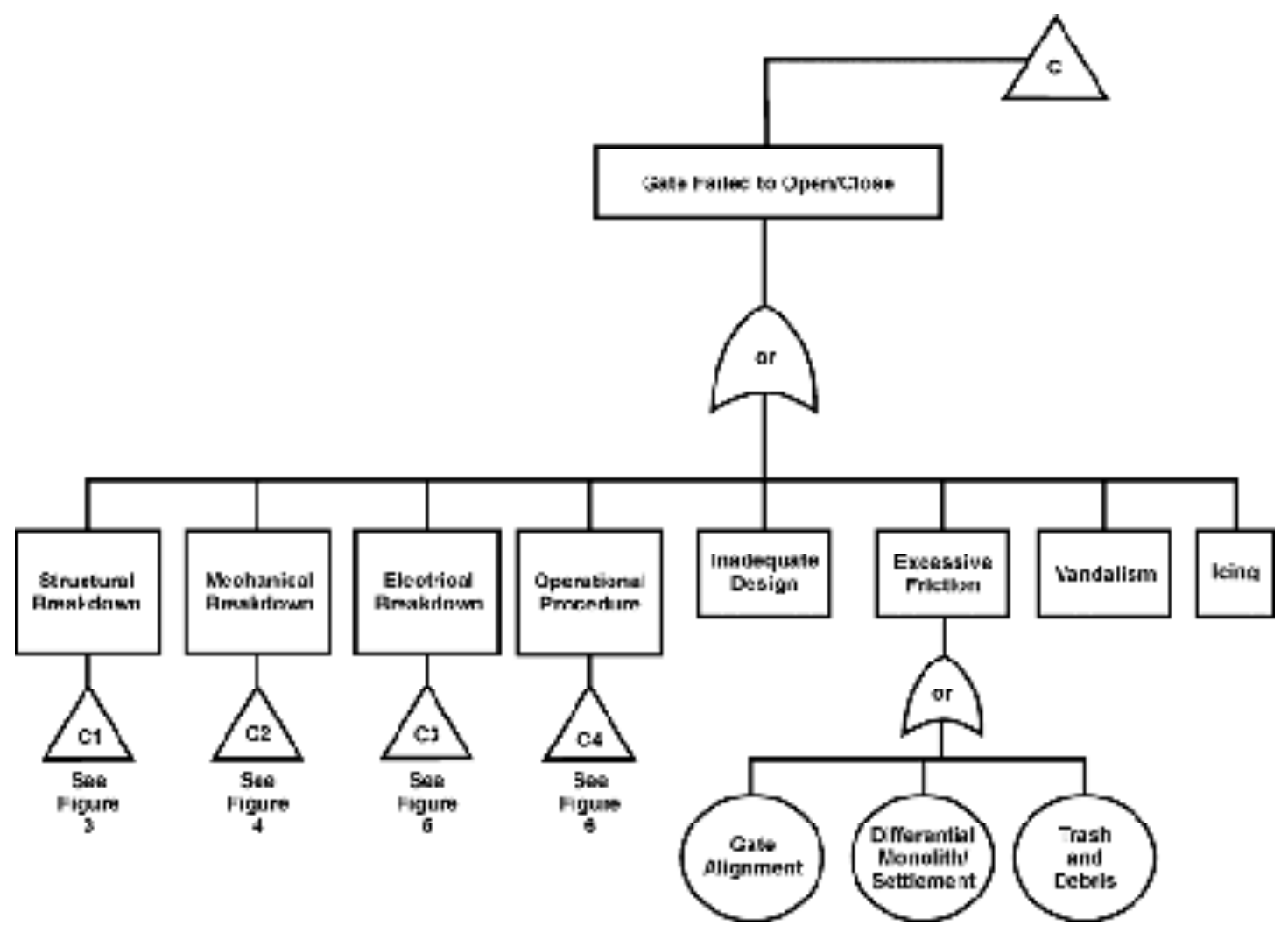

Figure 2. Fault tree for gate failures.

Examples of fault trees down-branching from the top events are shown in Figure 3, Figure 4, and Figure 5. These represent a basic breakdown of three critical branches: structural, mechanical, and electrical subsystems. The subsystems are connected to an up-event by the triangle. Subsequent to each of these bottom level events are the cause and consequence of each failure mode. For purposes of brevity, these are not directly defined in the boxes within the fault trees. Faults (i.e., causes) for the events identified for the subsystem represented in Figure $3-$ Figure 5 are presented in more detail in Table 1. 


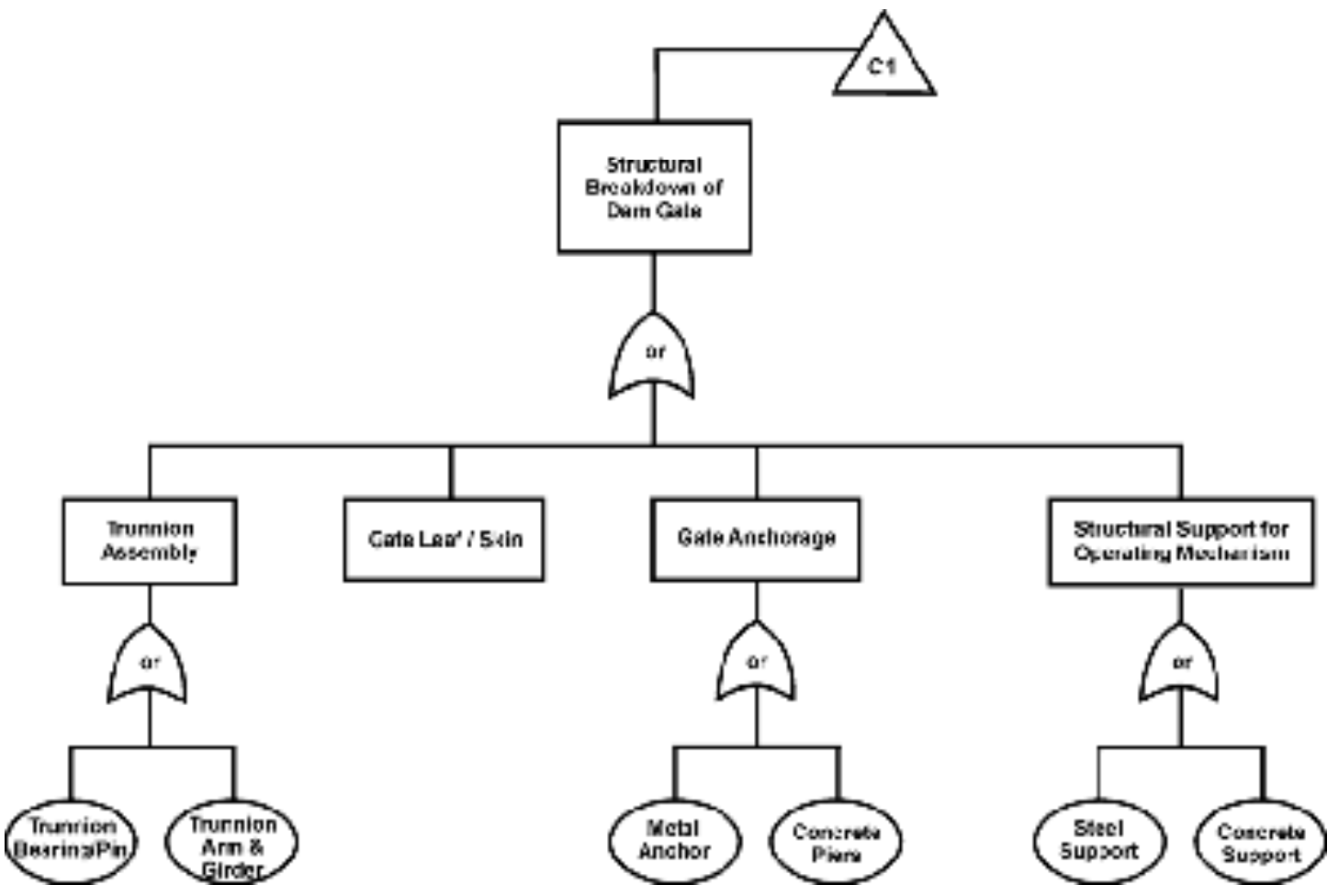

Figure 3. Fault tree for gate structural breakdown.

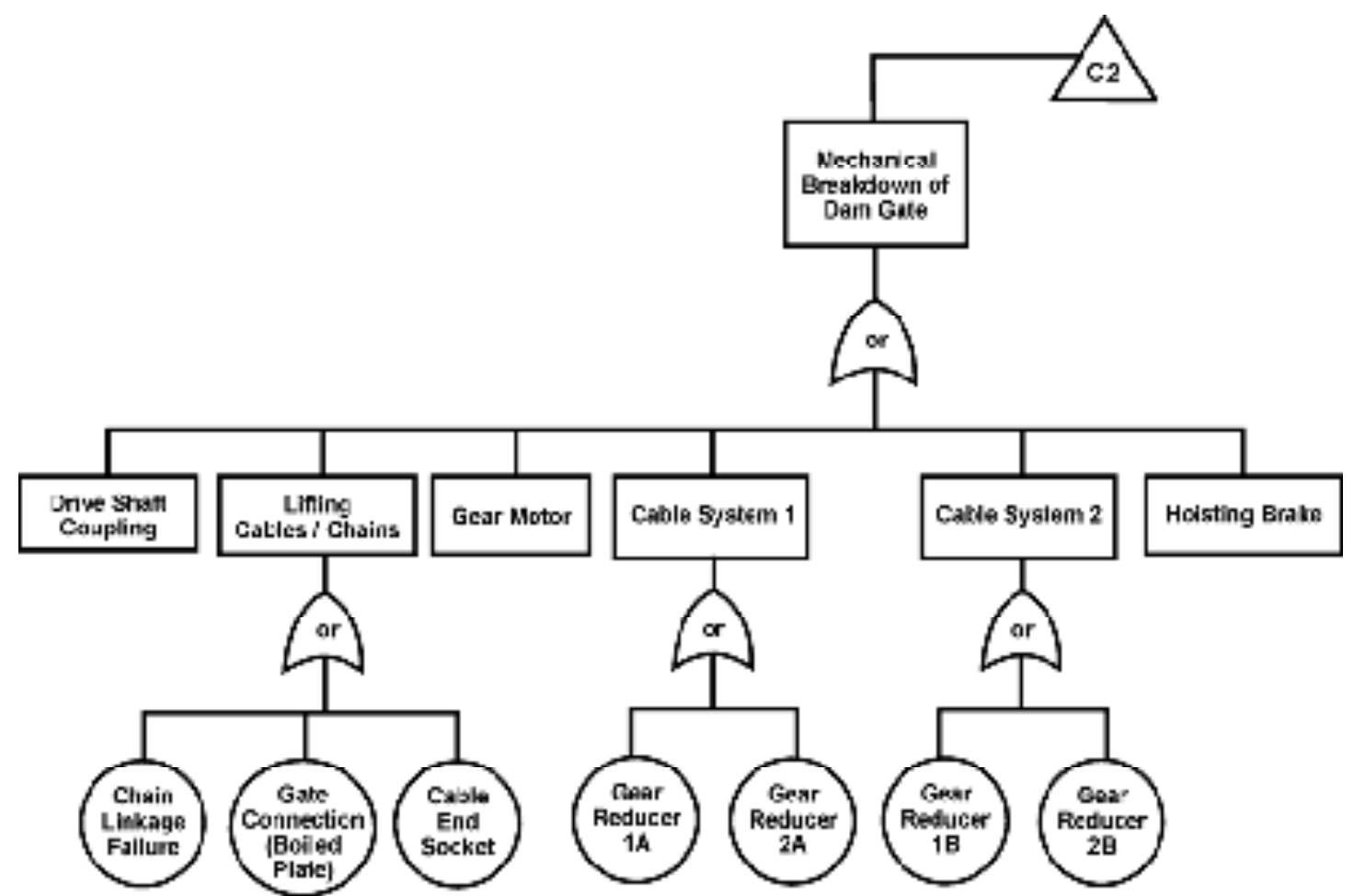

Figure 4. Fault tree for gate mechanical breakdown. 


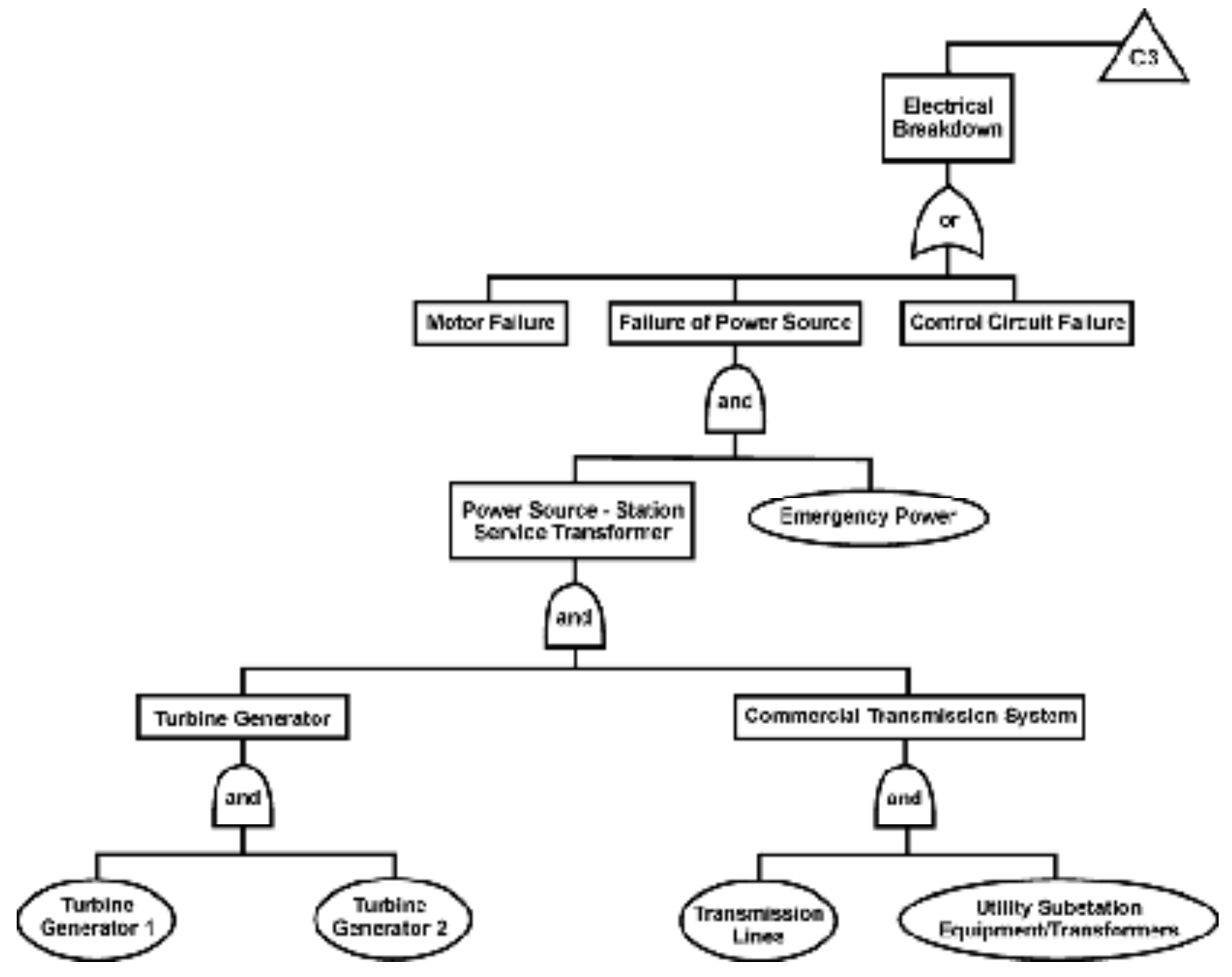

Figure 5. Fault tree for gate electrical breakdown.

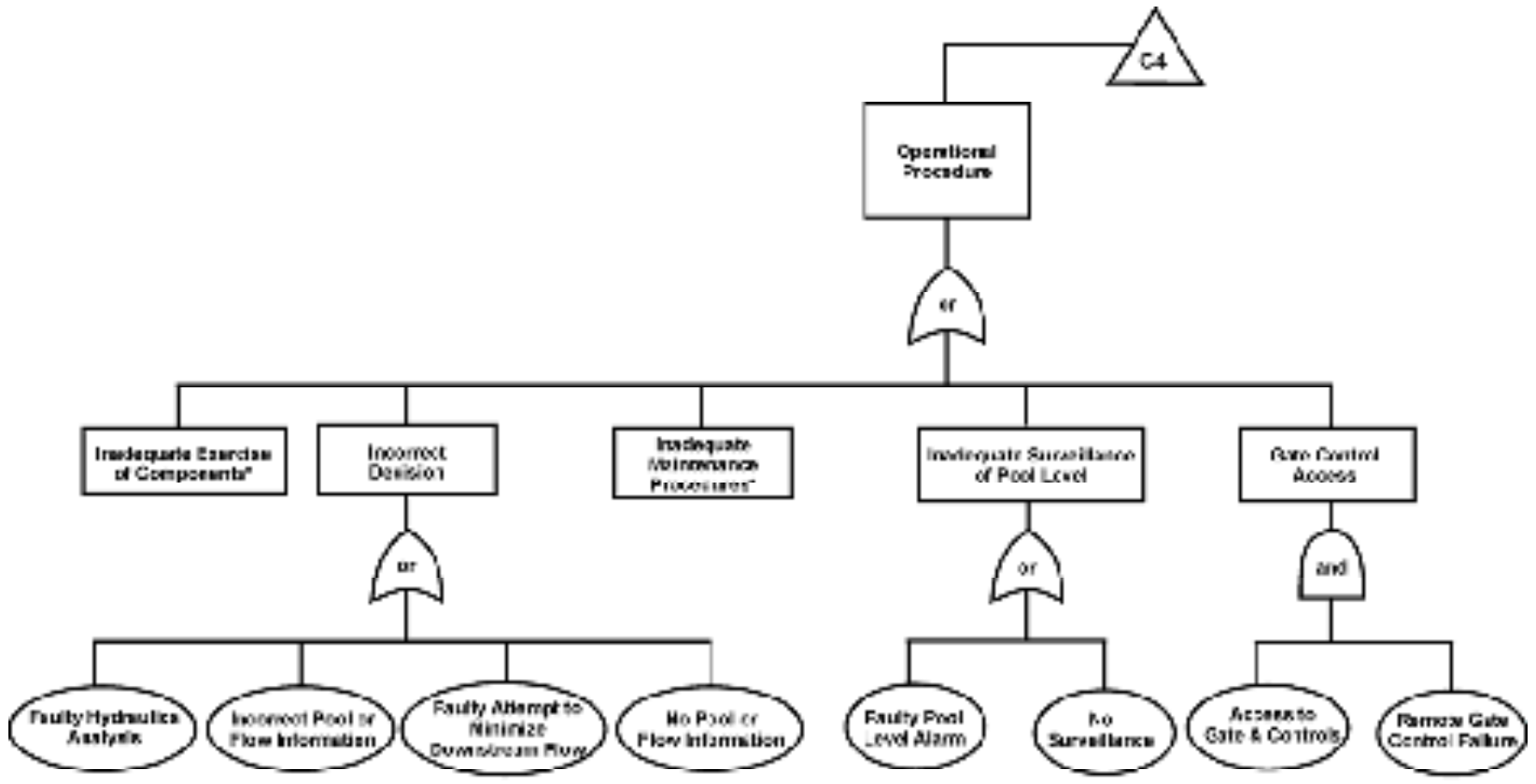

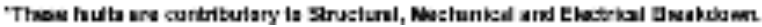

Figure 6. Fault tree for gate operational breakdown. 
Table 1. Example causes of failure events for fault trees shown in Figures $2-6$.

\begin{tabular}{|c|c|}
\hline Failure Event & Cause \\
\hline 1. Concrete Deterioration & $\begin{array}{l}\text { - Corrosion of R-Bar } \\
\text { - Cracks from overload } \\
\text { - Salt (chloride) or } \\
\text { - Sulfate reaction }\end{array}$ \\
\hline $\begin{array}{l}\text { 2. Inadequate Spillway } \\
\text { Capacity }\end{array}$ & $\begin{array}{l}\text { - Changes in PMF } \\
\text { - Changes in run-off as a result of increased development around lakes } \\
\text { and in drainage basin } \\
\text { - Political/public opposition to raising dam height or modifying spillway } \\
\text { gates } \\
\text { - Lack of funds to make necessary changes } \\
\text { - Poor maintenance of equipment } \\
\text { - Silt/debris build-up on front of gates and on the bottom of the pool } \\
\text { - Gate entrance blocked from ice dams or debris material during } \\
\text { discharge of flood event } \\
\text { - Failure of upstream dam }\end{array}$ \\
\hline 3. Broken Linkages & $\begin{array}{l}\text { - Failure of gear box } \\
\text { - Failure of cables/chains } \\
\text { - Failure of chain/cable attachment to gate } \\
\text { - Failure of driveline couplings (come apart) }\end{array}$ \\
\hline 4. Foundation Instability & $\begin{array}{l}\text { - Terrorism } \\
\text { - Overload from overtopping }\end{array}$ \\
\hline 5. Logs & $\begin{array}{l}\text { - Logs that hang up on top of gates and prevent opening } \\
\text { - Logs that could prevent gate closure } \\
\text { - Logs that could hang up on gates and cause hydraulic unbalance, } \\
\text { vibration and failure of gate }\end{array}$ \\
\hline 6. Ice & $\begin{array}{l}\text { - Ice that causes gates to be frozen closed } \\
\text { - Ice from leakage and wave splash over that builds up on gate and } \\
\text { prevents opening as a result of excessive hoist load. } \\
\text { - Ice that freezes gates in the open position } \\
\text { - Ice build-up on walkways, gate operating equipment that prevents } \\
\text { access to and operation of controls }\end{array}$ \\
\hline 7. Failure Of Trunnion Arm & $\begin{array}{l}\text { - Debris falling on arm } \\
\text { - Failure due to corrosion } \\
\text { - Icing } \\
\text { - High trunnion friction } \\
\text { - Overtopping }\end{array}$ \\
\hline 8. Failure of Gate Leaf/Skin & $\begin{array}{l}\text { - Corrosion } \\
\text { - Physical damage from debris } \\
\text { - Brittle fracture }\end{array}$ \\
\hline 9. Failure of Metal Anchor & $\begin{array}{l}\text { - Corrosion } \\
\text { - Fatigue } \\
\text { - Torsional loading } \\
\text { - Overloading }\end{array}$ \\
\hline $\begin{array}{l}\text { 10. Failure of Concrete } \\
\text { Piers }\end{array}$ & - Concrete deterioration \\
\hline
\end{tabular}




\begin{tabular}{|c|c|}
\hline Failure Event & Cause \\
\hline 11. Failure of Steel Support & $\begin{array}{l}\text { - Corrosion } \\
\text { - Overloading } \\
\text { - Fatigue } \\
\text { - Fasteners }\end{array}$ \\
\hline $\begin{array}{l}\text { 12. Failure of Concrete } \\
\text { Support }\end{array}$ & - Concrete Deterioration \\
\hline 13. Drive Shaft Coupling & $\begin{array}{l}\text { - Decoupling } \\
\text { - Keyway failure (key and keyway) } \\
\text { - Torsional failure of shaft }\end{array}$ \\
\hline 14. Gear Motor & $\begin{array}{l}\text { - Failure of gears } \\
\text { - Shaft failure } \\
\text { - Bearing failure }\end{array}$ \\
\hline 15. Gear Reducers & $\begin{array}{l}\text { - Bearing failure } \\
\text { - Gear failure (due to lack of lubrication, fatigue failure) } \\
\text { - Shaft failure } \\
\text { - Housing failure } \\
\text { - Sprocket/failure }\end{array}$ \\
\hline 16. Chain Linkage Failure & $\begin{array}{l}\text { - Loss of snap rings } \\
\text { - Corrosion }\end{array}$ \\
\hline $\begin{array}{l}\text { 17. Gate Connection } \\
\text { (Bolted Plate) }\end{array}$ & $\begin{array}{l}\text { - Connection itself } \\
\text { - Corrosion }\end{array}$ \\
\hline 18. Cable End Socket & - Corrosion \\
\hline 19. Hoisting Brake & $\begin{array}{l}\text { - Keyway failure } \\
\text { - Shoe failure } \\
\text { - Solenoid failure } \\
\text { - Torsional failure of spring }\end{array}$ \\
\hline 21. Transmission Lines & $\begin{array}{l}\text { - Ice } \\
\text { - Lightning } \\
\text { - Tornadoes }\end{array}$ \\
\hline $\begin{array}{l}\text { 22. Utility Substation } \\
\text { Equipment/ Transformers }\end{array}$ & $\begin{array}{l}\text { - Short circuit } \\
\text { - Lightning }\end{array}$ \\
\hline 23. Control Circuit Failure & $\begin{array}{l}\text { - Relays } \\
\text { - Control buttons }\end{array}$ \\
\hline 24. Motor Failure & $\begin{array}{l}\text { - Insulation failure } \\
\text { - Bearing failure } \\
\text { - Windings }\end{array}$ \\
\hline $\begin{array}{l}\text { 25. Inadequate Gate Seals } \\
\text { Side Seals } \\
\text { Bottom Seals }\end{array}$ & $\begin{array}{l}\text { - Weathering failure } \\
\text { - Abrasion due to debris } \\
\text { - Abrasion due to debris }\end{array}$ \\
\hline $\begin{array}{l}\text { Differential Monolith/ } \\
\text { Settlement }\end{array}$ & $\begin{array}{l}\text { - Foundation settlement/rebound } \\
\text { - Earthquake } \\
\text { - Seepage and piping } \\
\text { - Excessive friction } \\
\end{array}$ \\
\hline 27. Trash and Debris & - Due to trees, logs \\
\hline
\end{tabular}




\begin{tabular}{|c|c|}
\hline Failure Event & Cause \\
\hline \multicolumn{2}{|l|}{$\begin{array}{l}\text { 28. Galvanic Corrosion and/ } \\
\text { or Mineral Deposits }\end{array}$} \\
\hline Cables/Chains & $\begin{array}{l}\text { - Corrosion/mineral deposits } \\
\text { - Seizing of chains }\end{array}$ \\
\hline Trunnion Anchorage & $\begin{array}{l}\text { - Corrosion } \\
\text { - Brittle fracture }\end{array}$ \\
\hline Trunnion Bearings/Pin & - Inadequate lubrication \\
\hline Trunnion Arms and Girders & - Paint failure \\
\hline 29. Inadequate Design & $\begin{array}{l}\text { - All load conditions not assessed (dead weight, trunnion friction, wave } \\
\text { height and ride up) }\end{array}$ \\
\hline 30. Operational Procedure & $\begin{array}{l}\text { - Human error } \\
\text { - Inadequate hydraulic calculation capabilities } \\
\text { - Inadequate surveillance } \\
\text { - Motor on overload and operator fails to recognize it } \\
\text { - Annual gate operations test }\end{array}$ \\
\hline 31. Excessive Friction & $\begin{array}{l}\text { - Bearing failure } \\
\text { - Inadequate lubrication } \\
\text { - Misalignment } \\
\text { - Differential movement (resulting in gate binding) } \\
\text { - Alkali-aggregate reaction (vertical lift gates) }\end{array}$ \\
\hline 32. Vandalism & $\begin{array}{l}\text { - Due to sabotage of mechanical parts } \\
\text { - Due to sabotage of electrical controls/motors } \\
\text { - Due to sabotage of structural parts }\end{array}$ \\
\hline $\begin{array}{l}\text { 33. Maintenance } \\
\text { Procedures }\end{array}$ & $\begin{array}{l}\text { - Lubrication trunnion bearing } \\
\text { - Gear reducers } \\
\text { - Wire ropes/sockets inspections for damages protection for gates } \\
\text { - Heaters in gearboxes and controls } \\
\text { - Gate-side seal heaters } \\
\text { - Gate-air bubbler system } \\
\text { - Trash removal from in front of gate } \\
\text { - Insulation testing (electrical) }\end{array}$ \\
\hline 34. Icing & $\begin{array}{l}\text { - Gates frozen in closed position } \\
\text { - Gates frozen in open position }\end{array}$ \\
\hline 35. Lifting Devices & $\begin{array}{l}\text { - Access } \\
\text { - Icing/adverse weather conditions } \\
\text { - (See electrical, mechanical and structural breakdown for details) }\end{array}$ \\
\hline
\end{tabular}




\begin{tabular}{|l|l|}
\hline Failure Event & Cause \\
\hline 36. Access Restrictions & - Flooding \\
& - Washouts \\
& - Freezing rain \\
& - Tornado \\
& - Hurricane \\
& - Freezing mist during operation \\
& - Earthquake \\
\hline 37. Loss of Data Collection & - Lack of monitoring system \\
and Communication & - Unchecked monitoring data \\
& - Remote unmanned projects \\
& - Loss of communication links between data collection platforms \\
& (DCPs) and the central weather management centers \\
& - Satellite communication links down
\end{tabular}




\section{Prospective Methods for Prescreening Dam Gate Components}

The ability to prescreen components can save significant time and effort risk assessment for dam gates. Prescreening helps to identify redundancy of system components and to rank their overall importance and contribution to the final risk of the dam gates. Two methods can be used to assist with prescreening.

The first method focuses on the application of a criticality index using failure modes and effects analysis (FMEA). This method defines the risks for dam gates based on the probability of each mode of gate failure and a criticality index that accounts for all failure modes of all components in a gate system. Looking at the effect of each failure mode for a given component can significantly alter the assessment of risk. The second method applies a component's probability of failure to the functional and hardware criticality of each component. This functional and hardware criticality accounts for redundancy using predefined weighting functions based on component criticality.

Both of these methods are laid out using the fault tree analysis methods presented in Chapter 2, and they produce results that are different in significant ways.

\subsection{Criticality Index Method}

\subsubsection{Explanation of Method}

This method uses an approach that computes a criticality index for each failure mode of a component. Criticality can be defined as a relative measure of the consequences of a failure mode and its frequency of occurrence. Criticality indices are not considered a probability per se but are a realistic measure of the importance of their function within a gate system. This makes the criticality index extremely valuable to use in the prescreening of dam gate components and ranking of systems. 
The criticality index of a hardware component is defined by Ebeling (1997) as follows:

$$
\left.C_{k}=\alpha_{k p} \beta_{k} \lambda_{p} t \quad \text { (Equation } 1\right)
$$

where

$$
\begin{aligned}
& C_{k}=\text { the criticality index for failure mode } \mathrm{k} \\
& \alpha_{k p}=\text { the fraction of the component p's failures having failure } \\
& \beta_{k}=\text { the conditional probability that failure mode } \mathrm{k} \text { will result in } \\
& \text { the identified failure effect } \\
& \lambda_{p}=\text { the failure rate of component } \mathrm{p} \\
& t=\text { duration of time used in the analysis }
\end{aligned}
$$

To determine the criticality index using Equation 1, the parameters $\lambda, \alpha$, and $\beta$ must be determined for each failure mode of a component. It should be noted that $C_{k}$ determined from Equation 1 will be different for each of the failure modes, $k$, for a component. The typical procedure used for the criticality index method is described in the following steps:

1. Obtain the failure rate, $\lambda$, of the hardware component from the field data. This value will be common for all the associated failure modes of a component.

2. Obtain the factor, $\alpha$, which is the probability of occurrence for each failure mode associated with the hardware component. The following relation must be satisfied for all failure modes:

$$
\Sigma \alpha=1 \quad \text { (Equation 2) }
$$

3. Obtain the factor, $\beta$, which is the probability of occurrence of the failure effect once the identified failure mode has occurred. This value reflects on the weighting in the final criticality index. 
4. Calculate the criticality index, $C_{k}$, for a specified operation period or duration, $t$, of a system component using Equation 1. The duration, $t$, will be common for all failure modes.

An example of the criticality index method applied to an electrical system breakdown is presented below.

\subsubsection{Example for a Gate Electrical Subsystem}

The fault tree for a gate electrical breakdown is shown in Figure 7. The values of the relative importance of each component for each AND or OR event gate using a weighting factor $\left(\mathrm{W}_{\mathrm{i}}\right)$ is shown in Figure 7. Because criticality indices are not probabilities, typical fault tree multiplication cannot be invoked, so the weighting factors shown in Figure 7 are an estimate to relate the expected contribution of the component to the overall gate system. The following calculation shows an example to determine the criticality index for a turbine generator. The turbine generator 1 is defined as variable $C_{T G-1}$ at the bottom level of Figure 7 .

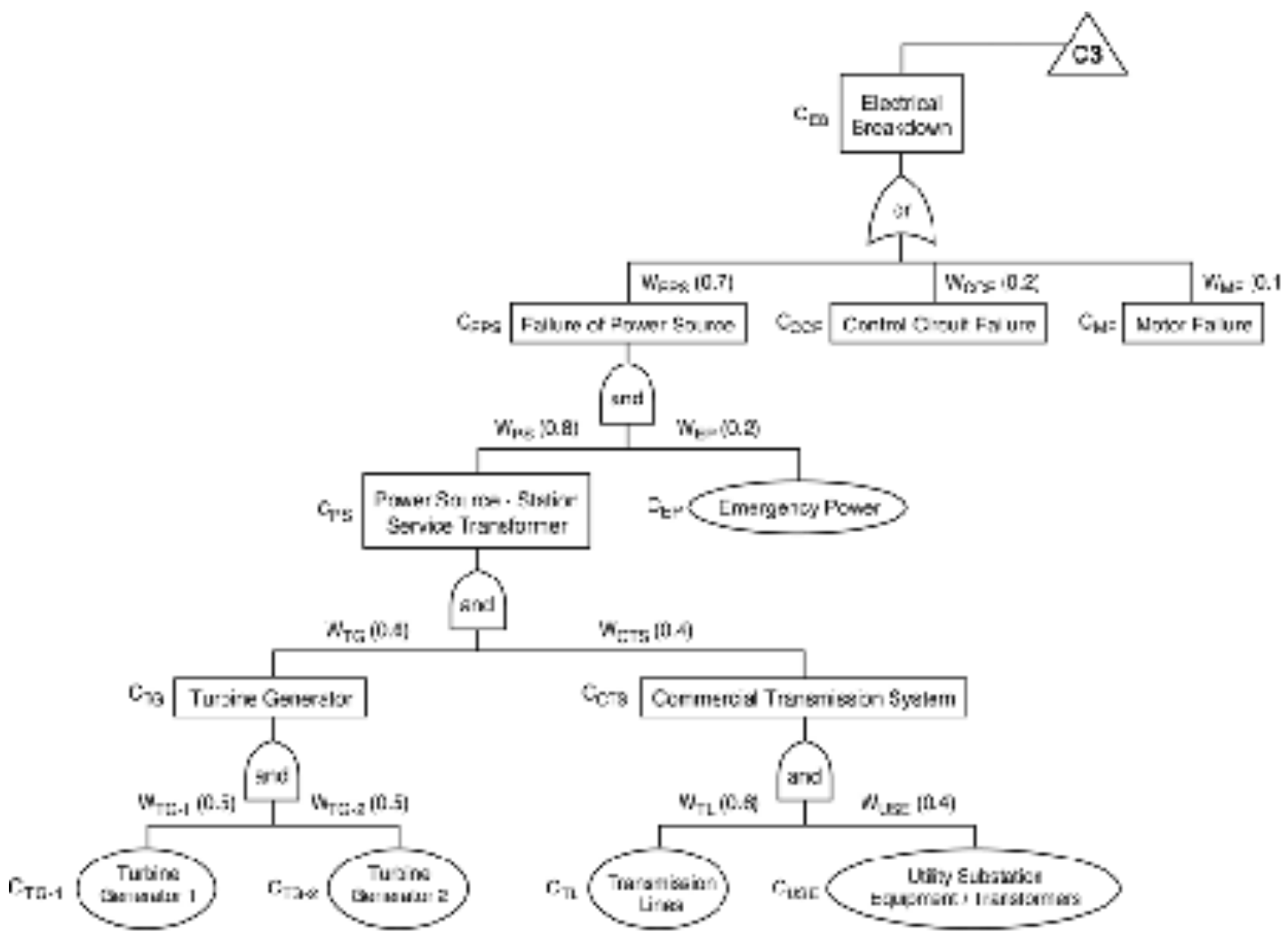

Figure 7. Dam gate electrical system example. 
The failure modes for the turbine generator component and corresponding criticality indices are shown in Table 2 . The value for the failure rate is taken from supplied industry data with expected values for $\lambda$, $\alpha$, and $t$.

$C_{T G-1}$ Bearing Failure $=\alpha_{k p} \beta_{k} \lambda_{p} t$

$$
\begin{aligned}
& =0.5 * 0.1 * 1.2 * 10^{-6} * 1000 \\
& =60 * 10^{-6}
\end{aligned}
$$

$=>C_{T G-1}($ total of all failure modes $)=468^{*} 10^{-6}$

Table 2. Example of criticality index values for a turbine generator.

\begin{tabular}{|l|l|l|l|l|l|l|}
\hline Component & $\begin{array}{l}\text { Failure } \\
\text { Mode }\end{array}$ & $\begin{array}{l}\text { Failure } \\
\text { Rate }\end{array}$ & Fraction & $\begin{array}{l}\text { Conditional } \\
\text { Prob. }\end{array}$ & Time & $\begin{array}{l}C_{k} \text { Criticality } \\
\text { Index } \\
\text { (from Eq. 1) }\end{array}$ \\
\hline & & $\lambda$ & $\alpha$ & $\beta$ & $t$ & \\
\hline $\begin{array}{l}\text { Turbine } \\
\text { Generator }\end{array}$ & $\begin{array}{l}\text { Bearing } \\
\text { Failure }\end{array}$ & $1.2 \times 10^{-6}$ & 0.5 & 0.1 & $\begin{array}{l}1000 \\
\mathrm{hrs}\end{array}$ & $60 \times 10^{-6}$ \\
\hline & $\begin{array}{l}\text { Stator } \\
\text { Failure }\end{array}$ & $1.2 \times 10^{-6}$ & 0.2 & 0.2 & $\begin{array}{l}1000 \\
\mathrm{hrs}\end{array}$ & $48 \times 10^{-6}$ \\
& $\begin{array}{l}\text { Governor } \\
\text { Failure }\end{array}$ & $1.2 \times 10^{-6}$ & 0.3 & 1.0 & $\begin{array}{l}1000 \\
\mathrm{hrs}\end{array}$ & $360 * 10^{-6}$ \\
\hline
\end{tabular}

Similarly, criticality indices can be calculated for the remainder of the components shown in Figure 7 to obtain the overall criticality index of the failure mode of electrical breakdown $\left(C_{E B}\right)$. Details of this calculation for the electrical system are shown in more detail in Chapter 4. Using the steps outlined in section 3.1 and multiplication through the fault tree, the $C_{E B}$ is calculated as $316^{*} 10^{-6}$. This value for the criticality of the electrical system can then be ranked against the other criticality indices from other branches of the fault tree shown in Figure 2. The results can also be combined for each subsystem in a similar manner to provide a criticality index for the entire gate system.

\subsection{Failure/Criticality Method}

\subsubsection{Explanation of Method}

The Mission Criticality method uses an approach that computes a weighted probability of failure for the gate system based on probabilities of failure and criticality of the lower level subcomponents. Criticality is introduced in this 
method in terms of a loss of mission (e.g., failure of gate to open/close) related to both the functional and hardware requirements of a component. Failure mode criticality for dam gates can be identified at a functional level, or a hardware component level, or a combination of the two. One method defined by Boeing Systems (1998) classifies failure modes according to the three levels defined below in Table 3.

Hardware criticality is designated by the numbers 1,2 , or 3 , as shown in Table 3. A hardware criticality of 1 indicates loss of dam gate through a single component failure. A hardware criticality of 2 indicates a loss of mission, which means that nonstandard methods are required to operate the gate and the failure of any redundant item would render the gate inoperable. A hardware criticality 3 indicates all other types of failure that do not cause loss of mission or operation.

Table 3. Hardware criticality (Boeing 1998).

\begin{tabular}{|c|l|}
\hline Criticality & Potential Effect of Failure \\
\hline 1 & Inoperable: gate will not open or gate will not close. \\
\hline 2 & Loss of redundant items requiring nonstandard methods for opening or closing gates. \\
\hline 3 & All others. \\
\hline
\end{tabular}

A functional criticality is designated by $1,1 \mathrm{R}, 2,2 \mathrm{R}$, or 3 as shown in Table 4 . A functional criticality of 1 indicates that loss of a single function could result in loss of the dam gate. A functional criticality of $1 \mathrm{R}$ indicates redundant hardware items which, if all failed to function, could cause loss of dam gate. A functional criticality of 2 indicates a single functional failure that could result in the loss of mission, requiring nonstandard methods for gate operation. A functional criticality of $2 \mathrm{R}$ indicates redundant hardware items which, if all failed, could cause loss of mission gate. A function criticality 3 indicates all other types of functional failure.

Table 4. Functional criticality (Boeing 1998).

\begin{tabular}{|c|l|}
\hline Criticality & Potential Effect of Failure \\
\hline 1 & Single failure that could result in an inoperable dam gate. \\
\hline $1 \mathrm{R}$ & $\begin{array}{l}\text { Redundant hardware item(s), all of which if failed, could result in an inoperable } \\
\text { dam gate. }\end{array}$ \\
\hline 2 & Loss of a single item requiring non-standard methods for opening or closing gate. \\
\hline $2 \mathrm{R}$ & $\begin{array}{l}\text { Redundant hardware item(s), all of which, if failed, could require non-standard } \\
\text { methods for opening or closing gate. }\end{array}$ \\
\hline 3 & All others. \\
\hline
\end{tabular}


These criticalities may be combined to reflect redundancy in the system. A failure mode may also be classified using a combined functional and hardware approach, as shown in Table 5. This notation can also include redundancy of components in the system, if there is any. The important thing to note is that a criticality classification of a combined failure mode consists of three characters if there is redundancy in the system (1R3, for example). The first character is a number that represents the functional criticality. The second character is an $R$ that represents redundancy in the system. The third character is a number representing the hardware criticality.

If there is no redundancy in the system, then the criticality classification of the failure mode consists of two characters (2/2, for example). The first number represents functional criticality and the second number represents hardware criticality. In either case, if the first character is 1 , it implies loss of gate whereas if the first character is 2 , it implies loss of mission with potential loss of gate for the present project. If the first character is 3 , it implies minimal or no effect.

Table 5. Combined criticality of the failure mode (Boeing 1998).

\begin{tabular}{|c|c|c|c|}
\hline $\begin{array}{l}\text { If the functional } \\
\text { criticality is: }\end{array}$ & $\begin{array}{l}\text { The hardware } \\
\text { criticality is: }\end{array}$ & $\begin{array}{l}\text { The combined } \\
\text { criticality is: }\end{array}$ & Comments \\
\hline 1 & 1 & $1 / 1$ & $\begin{array}{l}\text { The hardware criticality is } \\
\text { always } 1 .\end{array}$ \\
\hline $1 \mathrm{R}$ & $\begin{array}{l}2 \\
3\end{array}$ & $\begin{array}{l}\text { 1R2 } \\
\text { 1R3 }\end{array}$ & $\begin{array}{l}\text { Hardware criticality is } 2 \text { if a } \\
\text { total of two (2) failures could } \\
\text { cause loss of dam gate. } \\
\text { Hardware criticality is } 3 \text { if a } \\
\text { total of three (3) or more } \\
\text { failures are required for } \\
\text { potential loss of dam gate. }\end{array}$ \\
\hline 2 & 2 & $2 / 2$ & $\begin{array}{l}\text { The hardware criticality is } 2 \text { if } \\
\text { single failure requires } \\
\text { nonstandard methods for } \\
\text { opening or closing dam gate. }\end{array}$ \\
\hline $2 \mathrm{R}$ & 3 & $2 \mathrm{R} 3$ & $\begin{array}{l}\text { The hardware criticality is } 3 \text { if } \\
\text { two failures require } \\
\text { nonstandard methods for } \\
\text { opening or closing dam gate. }\end{array}$ \\
\hline 3 & 3 & $3 / 3$ & $\begin{array}{l}\text { The hardware criticality is } \\
\text { always } 3 \text {. }\end{array}$ \\
\hline
\end{tabular}

If, for example, a failure mode were classified as 1R3 it would indicate that there is redundancy in the system and only if three hardware items fail would there be loss of dam gate operation. Similarly, if a failure mode were classified as 2R3, again redundancy would be available in the system, but only two hardware items need fail to result in the loss of dam gate operation. Note that in the case of a 
functional criticality of 2 , the number of hardware failures needed for loss of normal gate operation is one less than the number indicated in the criticality of failure mode classification. For example, if a failure mode is classified as $2 / 2$, it is implied that a single hardware component failure could require nonstandard methods for opening or closing the gate.

Table 6 relates the criticality classification of the component in the system to a contributing weight that is used in conjunction with the defined fault tree. Weighting is used to prevent minor to noncritical items from influencing a potentially dominating probability of failure to the top event. This weighting feature makes this method a very powerful tool to use in the prescreening of dam gate components for ranking importance.

Table 6. Classification of failure modes (Boeing 1998).

\begin{tabular}{|l|l|l|}
\hline Criticality of Failure Mode & Classification of Failure Mode & Weight $\left(\mathbf{W}_{\mathbf{i}}\right)$ \\
\hline $1 / 1$ & CIL (Critical Items List) & 0.99 \\
$1 \mathrm{R} 2$ & $\begin{array}{l}\text { CIL (because it could result in } \\
\text { loss of gate) }\end{array}$ & 0.9 \\
$1 \mathrm{R} 3$ & CIL or non-CIL & 0.7 \\
$\begin{array}{l}\mathrm{R} n \\
(\mathrm{n}>3)\end{array}$ & CIL or non-CIL & $0.7^{(\mathrm{n}-2)}$ \\
\hline $2 / 2$ & CIL & 0.01 \\
$2 \mathrm{R} 3$ & CIL or non-CIL & 0.001 \\
$2 \mathrm{Rn}$ & CIL or non-CIL \\
$(\mathrm{n}>3)$ & & $0.001^{(\mathrm{n}-2)}$ \\
$3 / 3$ & Non-CIL & 0.001 \\
\hline
\end{tabular}

The following procedures describe how the method is implemented:

1. Classify the criticality of all failure modes for the components associated with a top event (e.g., the gate failed to open/close as shown in Figure 1) as 1/1, 1R2, etc...as shown in Table 2 for all the initiating events (e.g., mechanical breakdown, electrical breakdown, etc., as shown in Figure 2).

2. Assign the criticality value that was determined for each component in Step 1 with the associated weight factor as defined in Table 7.

3. The probability of failure of each component and failure mode needs to be determined either through available data or reliability calculations. 
4. Probability of failure to open/close gates can be calculated from a fault tree diagram of the gate subsystems starting from the bottom event and working to the top event in that branch shown in Figure 2. The same process is then applied to the system shown in Figure 2 to identify the probability of failure to open/close the gate system. This is done using fault tree multiplication from the AND or "OR gates, as indicated in the fault diagram (Figures $2-5$ ).

5. The probability of failure for each component is then weighted by multiplying times the appropriate factor identified in Step 2.

6. The probability of failure of the top event (e.g., the probability that the gate fails to open/close as shown in Figures 2 - 5) can then be calculated using fault tree multiplication for the AND (product of the probabilities) or OR (addition of the probabilities) gates.

An example of this probability method applied to the same electrical system breakdown defined in the example above is presented below.

A Critical Items List (CIL) corresponds to hardware items and failure modes that are critical and need immediate attention. For example, if a dam gate is hoisted by a set of non-redundant chains or wire ropes, as most are, those chains or ropes would be classified as a CIL. The basic principle of criticality analysis is to automatically classify any failure as a CIL if there is no redundancy in the system (e.g., 1/1, 2/2, etc.). In addition, if there are less than three redundant hardware critical components and if the failure would result in loss of life, then the failure mode (e.g., 1R2) is also classified as a CIL.

The other failure modes that could result in loss of life or loss of mission are classified as CIL or non-CIL depending on whether the system passes a redundancy screen for critical components). As stated earlier, note that when a failure mode is classified as $1 / 1,1 \mathrm{R} 2,2 / 2$, it is automatically a CIL item. On the other hand, if a failure mode is classified as $1 \mathrm{R} 3,2 \mathrm{R} 3$, or higher, then the failure mode could be a CIL or non-CIL depending on how critical the redundant items are to the failure of the system. This needs to be checked for all the redundant hardware items. If a hardware item passes all the redundancy screens, i.e., no loss of life or operations occurs, then the failure mode is non-CIL. Otherwise, the failure mode should be classified as CIL.

\subsubsection{Example of Probability of Failure and Mission Criticality Calculations}

The criticality ranking of the various electrical subsystem component failure modes is shown in Figure 8 and Figure 9. These values (e.g., 2R4 for a motor 
failure) are based on the classifications set forth in Table 2 and an understanding of the redundancy of the electrical system. An example calculation for the turbine generator used in the previous section is demonstrated.

Table 7. Example criticality index calculations for turbine generator.

\begin{tabular}{|l|l|l|l|l|l|}
\hline & $\lambda$ & $\alpha$ & $\beta$ & $t$ & $C_{k}$ \\
\hline Bearing Failure & $1.2 \times 10^{-6}$ & 0.5 & 0.1 & $1000 \mathrm{hrs}$ & $60 \times 10^{-6}$ \\
\hline Stator Failure & $1.2 \times 10^{-6}$ & 0.2 & 0.2 & $1000 \mathrm{hrs}$ & $48 \times 10^{-6}$ \\
\hline Governor Failure & $1.2 \times 10^{-6}$ & 0.3 & 1.0 & $1000 \mathrm{hrs}$ & $360 \times 10^{-6}$ \\
\hline \multicolumn{6}{|l|}{$C_{T G-1}=468^{*} 10^{-6}$} \\
\hline
\end{tabular}

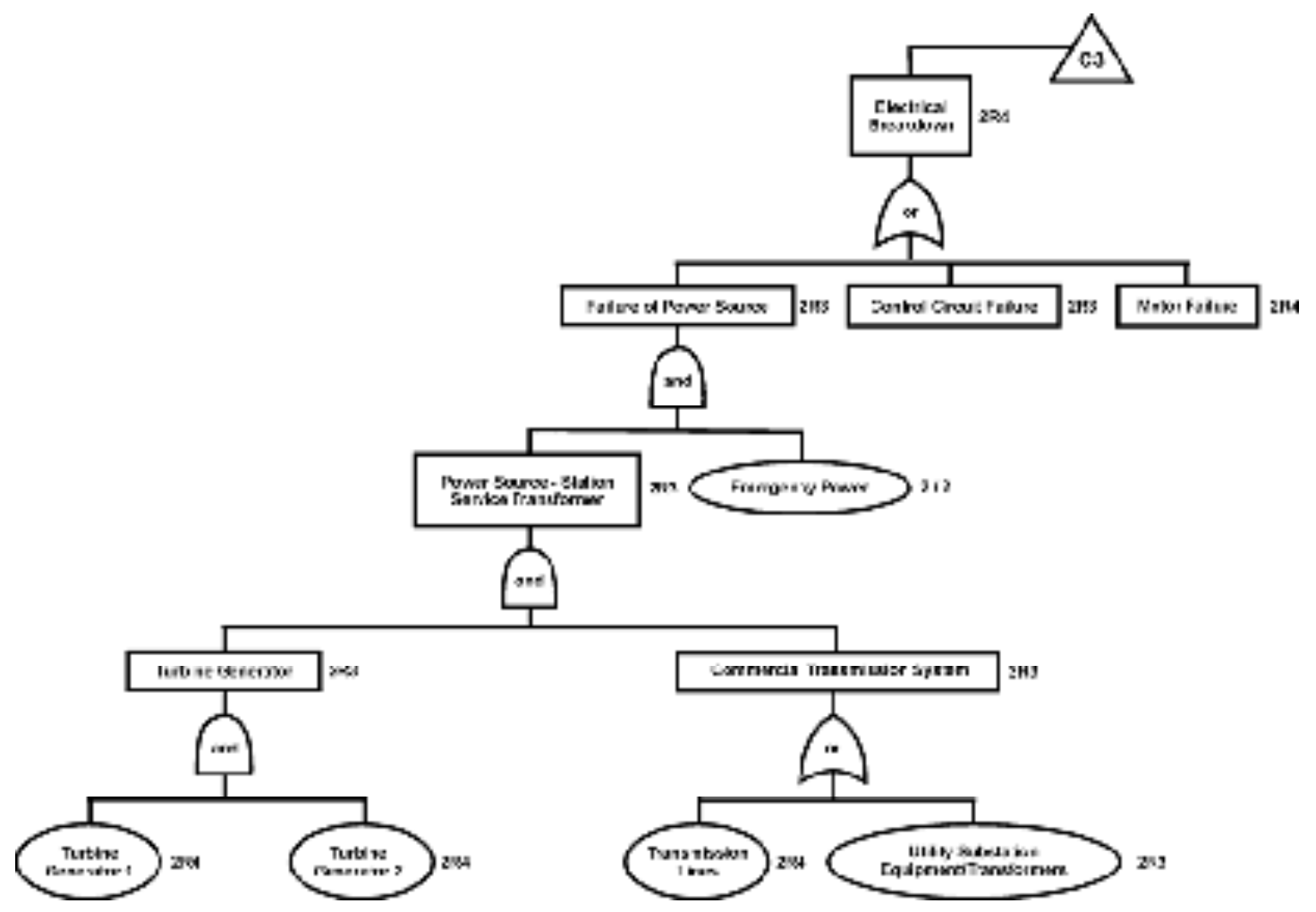

Figure 8. Example of ranking based on functional and hardware criticality. 


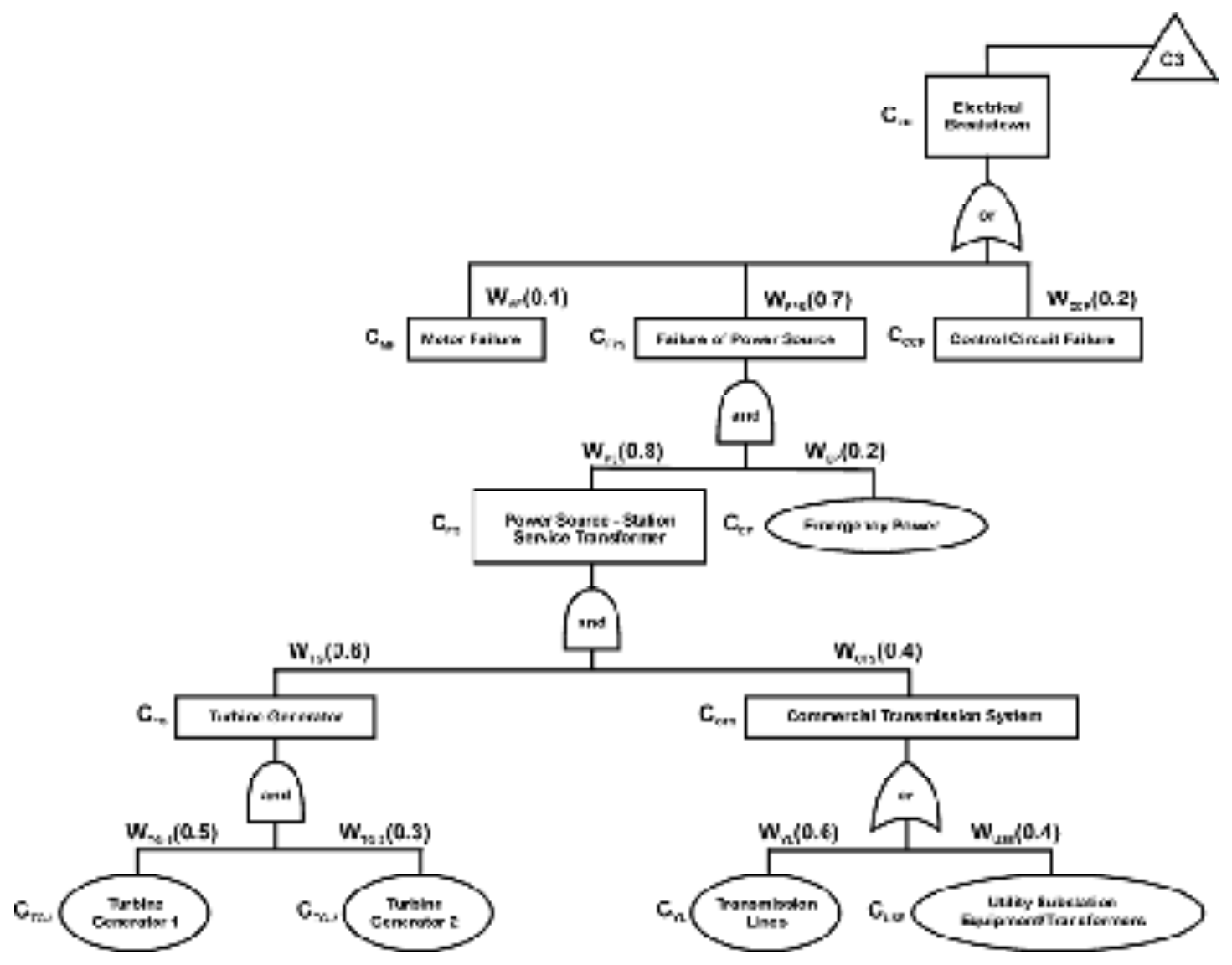

Figure 9. Classification of failure modes for electrical system example.

The failure modes of the turbine generator shown in Table 2 are bearing failure, stator failure, and governor failure. These can be classified as $2 \mathrm{R} 4$ as defined in Table 6. Table 7 defines the weight, $W_{T G-1}$ as $1 * 10^{-6}$. The exponential failure rate $\lambda$, and operating time $\mathrm{T}$ from MIL-STD-1629A for this equipment are $1.2 * 10^{-6}$ and 1000 hours, respectively.

$$
\begin{aligned}
& =>(R)_{T G-1}=e^{-\lambda t}=e^{-1.2 * 10^{-6} * 1000}=0.9988 \\
& \left(P_{f}\right)_{T G-1}=1.0-0.9988=0.0012 \\
& \left(P_{f}\right)_{T G-1} * W_{T G-1}=0.0012 * 1 * 10^{-6}=1.2 * 10^{-9}
\end{aligned}
$$

Similarly, failure probability values can be calculated for the remainder of the components shown in Figure 8 to obtain the overall probability of electrical breakdown $\left(P_{E B}\right)$. Using the steps outlined above and multiplication through the fault tree, the $P_{E B}$ is calculated as $2^{*} 10^{-7}$. These calculations are further detailed in Chapter 4. This failure probability value for the electrical system can then be used in the fault tree with the other probabilities of subsystem failure 


\section{Applications of Criticality Methods for Dam Gates}

The main purpose of the criticality analysis is to rank every possible failure mode for a particular hardware component identified in a Failure Modes and Effects Analysis (FMEA). The primary advantage of using criticality analysis is that it provides a common basis and consistent method for comparing various failure modes of a hardware component. Criticality is a procedure that uses each potential failure mode of a component in combination with the influence of both severity and the probability of occurrence. While the failure rate of a hardware component usually is the same for all the failure modes, the associated factors of severity and failure mode probability used in calculating the criticality index will be different for each failure mode and allow a distinction between critical and non-critical modes.

These methods have been advocated mainly in the Military Standard (MILSTD)-1629A, "Procedures for Performing a Failure Mode, Effects and Criticality Analysis" (1980). The methods also have been used and adopted by many engineering firms for the design of interdisciplinary engineering systems. One such example is found in the aerospace industry, where the procedures have been implemented both by Boeing and Lockheed-Martin in the design of complex aerospace systems such as the NASA (National Aeronautics and Space Administration) space shuttles. Because the criticality index is so flexible and broad, its applicability to infrastructure components such as flood control and reservoir dams make it a desirable method to incorporate into risk analysis.

\subsection{Criticality Index for Comparison of Gate Subsystems and Fault Trees}

\subsubsection{Explanation of Use}

The criticality index as defined by Equation 1 (page 13) requires the knowledge of parameters that may not be readily available from either manufacturer records, test data, or reliability textbooks. In addition, it is to be noted that $C_{k}$ in Equation 1 is different for each failure mode, $\mathrm{k}$, that uses the same failure rate $\lambda$, common to all failure modes. The criticality index of the hardware compo- 
nent can then be obtained by summing the $C_{k}$ values for all applicable $\mathrm{k}$, where $C_{k}$ is obtained from Equation 1. The following paragraphs summarize how to determine the criticality index parameters from Equation 1.

The failure rate, $\lambda$, can be determined using either failure rate data from the history of existing or similar gate components or the appendices found in MILSTD-1629A or other MIL-STD documents. These parameters are important to define correctly and should be researched as carefully as possible. If there is any uncertainty in the rates, a sensitivity analysis should be conducted to ensure that the final criticality index values do not vary by an order of magnitude. If values do vary by an order of magnitude, then further analysis and investigation will be required to develop a more accurate failure rate for that component.

The component failure rate, $\lambda$, can be determined from the mean time between failures (MTBF) of gate components (assuming similarity in operating environments, cycles, age, etc.) from:

$$
\left.\lambda=\frac{1}{M T B F} \quad \text { (Equation } 3\right)
$$

If there are no reported failures of the components or no similar components, then $\lambda$ can be estimated using the following relationship (Lock 1995):

$$
\lambda=\frac{x^{2}}{2 t}
$$

(Equation 4)

This equation is based on the assumption that the probability that no more than $\mathrm{t}$ time is required for $\mathrm{n}^{\text {th }}$ failure to appear can be obtained from finding what percentage point $2 \lambda \mathrm{t}$ is of the chi-square distribution with $2 \mathrm{n}$ degrees of freedom. For $n=1$, the corresponding chi-square has two degrees of freedom. In other words, chi-square distribution for two degrees of freedom is the exponential distribution with failure rate of $\lambda$ given by Equation 4 above. Then for a given problem, if the total operating hours of a component are known with no failure, then a predicted failure rate $\lambda$ can be obtained from Equation 4 . The $x^{2}$ value can be obtained for two degrees of freedom and a required confidence level from the chisquare tables found in statistical textbooks. For example, with two degrees of freedom and using a 50\% confidence level to maintain the exponential distribution for the failure rate, the value for $x^{2}$ would be 1.386 (Walpole and Myers 1993). 
The determination of $\alpha$, the probability of occurrence of the failure mode, would be most desirable to obtain from the engineers working at the actual dam site since they would be most familiar with the different failure modes for the failure modes and the approximate percentages that they occur. This information may also be contained in maintenance record books or purchase requests for the dam site. This would also be a parameter for which it is necessary to assess sensitivity to ensure that a questionable input value does not dominate the criticality index calculations. Also, it is important to remember that the sum of the $\alpha$ 's must equal 1. Again, in certain industries such as aerospace, this information is available for electrical components from Failure Mode/Mechanism Distributions (RAC 1991).

The determination of $\beta$, the probability of occurrence of the failure effect once the mode has been identified, is related to the failure mode of a hardware component and indicates whether the failure mode will result in actual loss (i.e., $\beta=1.0$ ), no effect or loss (i.e., $\beta=0.0$ ), or some possible effect or loss (i.e., $\beta$ between 0.001 to 0.999$)$. This value would be best obtained from engineers who are familiar with the dam site and understand the components and their effects on the overall dam gate system.

A detailed example of the calculations for the electrical subsystem presented in Chapter 3 is presented below.

\subsubsection{Example of Calculation for Electrical Subsystem of Dam Gates}

The values for the criticality and appropriate weights $\left(\mathrm{W}_{\mathrm{i}}\right)$ are shown in Table 7 for various components as related to the electrical subsystem. The following example uses values from Table 6 (in Chapter 3) and Table 7 to calculate the criticality index. The following steps highlight the process:

Step 1: Criticality index of turbine generator $1\left(C_{T G-1}\right)$

The failure modes for the hardware component turbine generator from Figure 9 are given in Table 7 along with values for $\lambda, \alpha, \beta$, and $t$ taken from MIL-STD$1926 \mathrm{~A}$.

Step 2: Criticality index of turbine generator $2\left(C_{\mathrm{TG}-2)}\right.$

Assuming that the turbine generator 2 has the same criticality index as turbine generator 1 , 


$$
C_{T G-2}=C_{T G-1}=468 * 10^{-6}
$$

Step 3: Criticality index for turbine generators $\left(C_{T G}\right)$

This value can be obtained using the information indicated for each of the associated components in Table 7 as,

$$
C_{T G}=0.5^{*} C_{T G-1}+0.5 * C_{T G-2}=468 * 10^{-6}
$$

If these turbine components were totally independent then the criticality index would have been $936 \times 10^{-6}$.

Step 4: Criticality index of transmission lines $\left(C_{T L}\right)$

The criticality index of transmission lines can be calculated for values of $\lambda=0.2 * 10^{-6}, \alpha=1.0, \beta=1.0, \mathrm{t}=1000$ hours using Equation 1 . The criticality becomes:

$$
C_{T L}=200 \times 10^{-6}
$$

Step 5: Criticality index of utility substation equipment $\left(C_{U S E}\right)$

This value can be calculated using the parameters of $\lambda=0.3^{*} 10^{-6}, \alpha=1.0, \beta=$ 1.0, $\mathrm{t}=1000$ hours using Equation 1. The criticality becomes:

$$
C_{\text {USE }}=300 \times 10^{-6}
$$

Step 6: Criticality index of commercial transmission system $\left(C_{T S}\right)$

The rollup of the values for the transmission system can be calculated using the values in Table 7 for each of the associated components, and the criticality of the system becomes:

$$
C_{T S}=0.6 * 200 * 10^{-6}+0.4 * 300 * 10^{-6}=120 * 10^{-6}+120 * 10^{-6}=240 * 10^{-6}
$$

Step 7: Criticality index of power sources $\left(C_{P S-1}\right)$

The rollup of the values for the power sources can be calculated using the values in Table 7 for each of the associated components, and the criticality of the system becomes:

$$
C_{P S-1}=0.6 * 468 * 10^{-6}+0.4 * 240 * 10^{-6}=280.8 * 10^{-6}+96 * 10^{-6}=376 * 10^{-6}
$$


Step 8: Criticality index of emergency power $\left(C_{E P}\right)$

This value can be calculated using the parameters of $\lambda=0.4 * 10^{-6}, \alpha=1.0, \beta=$ 1.0, $\mathrm{t}=1000$ hours using Equation 1. The criticality becomes:

$$
C_{E P}=400 * 10^{-6}
$$

Step 9: Criticality index of failure of power source $\left(C_{F P S}\right)$

The rollup of the values for the power sources can be calculated using the values in Table 7 for each of the associated components, and the criticality of the system becomes:

$$
C_{F P S}=0.8 * 376 * 10^{-6}+0.2 * 400 * 10^{-6}=300.8 * 10^{-6}+80 * 10^{-6}=380 * 10^{-6}
$$

Step 10: Criticality index of control circuit failure $\left(C_{C C F}\right)$

This value can be calculated as in step 1 from the assumed values of $\lambda=0.2 * 10$. ${ }^{6}, \alpha=1.0, \beta=1.0, \mathrm{t}=1000$ hours as

$$
C_{C C F}=200 * 10^{-6}
$$

Step 11: Criticality index of motor failure $\left(C_{M F}\right)$

This value can be calculated as in Step 1 from the assumed values of $\lambda=0.1 * 10$. ${ }^{6}, \alpha=1.0, \beta=1.0, \mathrm{t}=1000$ hours as

$$
C_{M F}=100 * 10^{-6}
$$

Step 12: Criticality index of the failure mode of electrical subsystem $\left(C_{E B}\right)$

Finally, the rollup of all the values for the electrical subsystem can be calculated using the fault tree shown in Figure 9 for each of the associated components. The criticality of the system becomes:

$$
\begin{gathered}
C_{E B}=0.7 * 380 * 10^{-6}+0.2 * 200 * 10^{-6}+0.1 * 100 * 10^{-6} \\
=266 * 10^{-6}+40 * 10^{-6}+10 * 10^{-6} \\
=316 * 10^{-6}
\end{gathered}
$$


A criticality index for other fault branches as shown in Figure 3 and Figure 5 for the structural breakdown $\left(C_{S B}\right)$ and mechanical breakdown $\left(C_{M B}\right)$ can be calculated using similar criticality index methods. After all the fault tree branches are complete, the criticality index for entire gate, i.e., $C_{G A T E}$, can be rolled up and calculated. This methodology can be extended further to encompass all the criticality indices for the failure modes shown in Figure 1 to include such items as obstructions $(C O B)$ and broken linkages $\left(C_{B L}\right)$. Finally, the criticality index of the top event, i.e., failure of dam spillway systems (CFAILURE-DAM-SPILLWAY), can be calculated. Because the criticality indices of all types of events, including basic, intermediate, and top, are available, a comparison can be made as to the relative performance of various components of the system (e.g., CFAULTY-Gates versus CINADEQUATE-SPILLWAY-CAPACITY).

\subsection{Failure Probability Method for Comparison of Gate Subsystems and Fault Trees}

\subsubsection{Explanation of Use}

The method developed to incorporate both the probabilities and redundancies of the gate system is defined in the following steps:

1. Classify criticality of all failure modes associated with the main event (such as gate failed to open/close) as 1/1, 1R2, etc., using the methodology described previously for all the initiating events as illustrated in Figure 2 - Figure 6 for the case of gate failure.

2. Calculate the probability of failure for each mode from the fault tree diagrams in Figure 2 - Figure 6, starting from the bottom-most basic event. This calculation would be done using the AND/OR logic gates as shown and appropriate fault tree mathematics that follow the gates in the fault tree diagrams.

3. Calculate the probability of failure of the top event, such as the failure of the gate to open or close, using the following equation for the case of an OR logic gate:

$$
P[\text { MainFailureMode }]=\Sigma W_{i} P_{f i} \quad \text { (Equation 5) }
$$

where

$W_{i}=$ Weight factor assigned to the subsystem (such as mechanical breakdown) of the failure mode (Table 5) 
$P_{f i}=$ Probability of failure of the subsystem (such as mechanical breakdown) of the failure mode

If the top event and the associated events are connected through the AND gate then, the summation $(\Sigma)$ sign in Equation 5 is replaced with the product $(\Pi)$ sign.

\subsubsection{Example of Calculation for Electrical Subsystem}

The critical ranking of various failure modes for the electrical subsystem is shown in Figure 9. The exponential distribution, which is commonly used to define the reliability of electrical and mechanical equipment, is used to calculate the probability of failures in this example. The following steps highlight the probability of failure process:

Step 1: Probability of failure of turbine generator 1 (TG-1)

The failure modes of a turbine generator from Table 1 are bearing failure, stator failure, and governor failure. These generators have been classified as $2 \mathrm{R} 4$. The criticality weight, $W_{T G-1}$ from Table 7 is $1 * 10^{-6}$. The failure rate $\lambda$ is from the previous examples as $1.2 * 10^{-6}$. The reliability of the turbine generators is:

$$
=>(R)_{T G-1}=e^{-\lambda t}=e^{-1.2 * 10^{-6} * 1000}=0.9988
$$

The probability of failure for the generators is the converse of the reliability, or $\mathrm{P}_{\mathrm{f}}=1-\mathrm{R}$ :

$$
\left(P_{f}\right)_{T G-1}=1.0-0.9988=0.0012
$$

Step 2: Probability of failure of turbine generator 2 (TG-2)

Assume the failure probability of turbine generator $2\left(\left(P_{f}\right)_{\mathrm{TG}-2)}\right)$ is the same as TG1.

$$
=>\left(P_{f}\right)_{T G-2}=.0012
$$

The criticality weight, $W_{T G-2}$, is $1 * 10^{-6}$ from Table 7 , as the failure modes of a turbine generator are classified as $2 \mathrm{R} 4$.

Step 3: Probability of failure of turbine generator (TG) 
Probability of turbine generator failure can be calculated from the following expression (using AND gate in Figure 9 and corresponding weight values in Table 7):

$$
\begin{gathered}
\left(P_{f}\right)_{T G}=\left(P_{f}\right)_{T G-2} * W_{T G-2} *\left(P_{f}\right)_{T G-2} * W_{T G-2} \\
=(0.0012) *\left(1 * 10^{-6}\right) *(0.0012) *\left(1 * 10^{-6}\right) \\
=1.44 * 10^{-18}
\end{gathered}
$$

This value for the generators indicates that the redundancy of the generator system makes the probability of failure very low. This result should be expected for highly redundant components.

Step 4: Probability of failure of transmission lines (TL)

For transmission lines $(T L)$, using a literature value of $\lambda=0.2 * 10^{-6}$ and $W_{T L}=$ $1 * 10^{-6}$,

$$
T L=e^{-\lambda t}=1-e^{-0.2 * 10^{-6} * 1000}=1-0.9998=0.0002
$$

Step 5: Probability of failure of utility substation equipment (USE)

For utility substation equipment using the value of $\lambda=0.3 * 10^{-6}, W_{U S E}=0.001$,

$$
\begin{aligned}
\left(P_{f}\right)_{U S E}=1-e^{-\lambda t} & =1-e^{-.3 * 10^{-6} * 1000}=1-0.99970 \\
& =0.00030
\end{aligned}
$$

Step 6: Probability of failure of commercial transmission system (CTS)

For commercial transmission system using an AND gate as shown in Figure 9,

$$
\left(P_{f}\right)_{C T S}=\left(P_{f}\right)_{T L} * W_{T L}\left(P_{f}\right)_{U S E} * W_{U S E}=\underset{17}{(0.0002) *\left(1 * 10^{-6}\right)(0.00030) * 0.001=6 * 10^{-}}
$$

Step 7: Probability of failure of power source 1(PS-1)

For power source 1 (PS-1), using AND gate (Figure 9 ), $W_{T G}$ as 0.001 , and $W_{C T S}$ as 0.002 , the corresponding probability of failure can be calculated as: 


$$
\begin{gathered}
\left(P_{f}\right)_{P S-1}=\left(P_{f}\right)_{T G} * W_{T G} *\left(P_{f}\right)_{C T S} * W_{C T S} \\
=\left(1.44 * 10^{-18}\right) *(.001)\left(6 * 10^{-17}\right) *(.001) \\
=8.64 * 10^{-41}
\end{gathered}
$$

Step 8: Probability of failure of emergency power (EP)

For emergency power the failure rate has a value of $\lambda=.4 * 10^{-6}$ and $W_{E P}=0.01$, the $\mathrm{P}_{\mathrm{f}}$ can be calculated as:

$$
\left(P_{f}\right)=1-e^{-\lambda t}=1-e^{-.4 * 10^{-6} * 1000}=4 * 10^{-4}
$$

Step 9: Probability of failure of power source (FPS)

For failure of power source using an AND gate with $W_{P S-2}=0.001$ and $W_{E P}=0.01$,

$$
\begin{gathered}
\left(P_{f}\right)_{F P S}=\left(P_{f}\right)_{P S-1} * W_{P S-1} *\left(P_{f}\right)_{E P} * W_{E P} \\
=\left(8.64 * 10^{-41}\right) *(0.001)\left(4 * 10^{-4}\right) *(0.01) \\
=34.56 * 10^{-50}
\end{gathered}
$$

Step 10: Probability of control circuit failure (CCF)

For control circuit failure for the value of $\lambda=0.2 * 10^{-6}$ and the value for $\mathrm{W}_{\mathrm{CCF}}=$ 0.001 ,

$$
\left(P_{f}\right)_{C C F}=1-e^{-\lambda t}=1-e^{-.2 * 10^{-6} * 1000}=.0002
$$

Step 11: Probability of motor failure (MF)

For motor failure the value for $\lambda=.1 * 10^{-6}$ ) and the value for $W_{M F}=1 * 10^{-6}$ :

$$
\left(P_{f}\right)_{M F}=1-e^{-\lambda t}=1-e^{.1 * 10^{-6} * 1000}=1-0.9999=0.0001
$$

Step 12: Probability of failure of electrical breakdown (EB) 
For electrical breakdown using OR gate with $W_{F P S}=0.001, W_{C C F}=0.001, W_{M F}=$ $1 * 10^{-6}$,

$$
\begin{gathered}
\left(P_{f}\right)_{E B}=\left(P_{f}\right)_{F P S} * W_{F P S}+(P)_{C C F} * W_{C C F}+\left(P_{f}\right)_{M F} * W_{M F} \\
=\left(34.56 * 10^{-50}\right) * 0.001+(0.0002) * 0.001+0.0001 *\left(1 * 10^{-6}\right) \\
=0.03 * 10^{-50}+2 * 10^{-7}+1 * 10^{-10} \\
=2 * 10^{-7}
\end{gathered}
$$

This value is very close in magnitude to others found in the literature. Similarly, the $P_{f}$ for other failure modes shown in Figure 2, such as for structural breakdown $\left(P_{f}\right)_{S B}$, can be calculated using these probability of failure values: $\left(P_{f}\right)_{\text {GATE }}$ can be calculated by adding failure probabilities for other failure modes shown in Figure 2 , such as obstructions $\left(\left(P_{f}\right)_{O B}\right)$ and broken linkages $\left(\left(P_{f}\right)_{B L}\right)$.

Finally, the probability of failure of the top event (failure of dam spillway) can be calculated. Because the failure probabilities for all basic, intermediate, and top events are available, a comparison of probabilities can easily be made to determine the relative importance of various components of the system, $\left(P_{f}\right)_{\text {Faulty-Gates }}$ and $\left(P_{f}\right.$ INADEQUATE-SPILLWAY-CAPACITY. The results can then be used to tangibly support maintenance and repair funding requests. 


\section{Spillways and Dam Gate Risks}

The risk assessment method discussed in this chapter provides a prioritization ranking procedure that accounts for both time and event dependencies. The procedure also determines a quantitative value for risk that can be compared at the component, project, or system-wide portfolio level. This risk assessment method is adaptable to the level of inputs but provides a consistent methodology for the prioritization and reduction of risk based on both component and dam. Therefore this procedure is flexible enough to be used for both pre-screening levels and more complex, detailed dam safety investigations.

The method has been adapted from a literature search and a summary of risk assessment methods by Putcha and Patev (2000). Putcha and Patev summarize various risk assessment procedures available in the literature that could be used to best analyze the risk assessment for dam gates. Putcha and Patev recommend using an adapted Lafitte method in combination with failure modes and effects criticality analysis to address the risk for spillway gates based on the levels for structural, geotechnical, mechanical, and electrical components.

Lafitte (1993) utilized the risk method defined by Bury and Guenter (1984) in which risk was defined as:

$$
R=P \times D^{a} \quad \text { (Equation 6) }
$$

where $\mathrm{R}$ is the risk measured as the extent of danger

$\mathrm{P}$ is the probabality of occurrence of the undesirable event

$\mathrm{D}$ is the probable extent of the damage

$a$ is the risk consequence factor

(Note: The value for $a$ is typically taken as 1 and can range between 1 to 2 )

From the expression above, the probabilities defined using the either method described in Chapter 4 can be combined with a set of consequences to determine the risks associated with the gate failing in the open or closed position. This factor relates to spillway risk as one of the top spillway events as defined in Putcha and Patev (2000). If, for example, the probability of a gate to fail opened or closed was $1 \times 10^{-2}$ and the damages from the event were $1 \times 10^{6}$ dollars, then the 
overall risk to the spillway system from the dam gates would be $\$ 100,000$ (assuming an $\alpha=1$ ). A $\alpha$ greater than 1 would indicate an aversion to catastrophic losses greater than the probabilistic calculation of monetary damage.

A detailed literature review was conducted as part of this research project to see if it is possible to arrive at a suitable range of values for the risk consequence factor, $\alpha$, for dam gates in Equation 6. No literature pertaining to that risk factor was found, but a nonlinear relationship could be determined based on the probabilities of failure for dam components as defined later in this chapter. In addition, if data were available on the probabilities and costs of existing dam gate failures, then one way to obtain $\alpha$ would be to take the logarithm of both sides of Equation 6 as follows:

$$
\log \mathrm{R}=\log \mathrm{P}+\alpha \log \mathrm{D} \quad \text { (Equation 7) }
$$

That operation transforms Equation 6 into a linear form, and the $\alpha$ can then be estimated using a regression analysis. For various components of a dam, it may be possible to estimate this value knowing the risks of dam failure and the anticipated damages from a gate failure.

Lafitte used this equation for risk in the application to address safety issues related to the overtopping of dams. Lafitte's equation has been further developed in this report to assist with the development of the relative risks for different components (i.e., structural, geotechnical, mechanical, and electrical) of a dam gate system to assist with dam portfolio risk assessment and risk prioritization and reduction. Equation 6 above can be redefined to account for the risk of a single component based on pools, probabilities of failure, and the extent of damages. This equation then becomes modified as:

$R=\stackrel{\stackrel{\mathrm{n}}{\mathrm{a}}}{\mathrm{i}} P_{\mathrm{i}} F_{\mathrm{i}} D_{\mathrm{i}}^{a_{\mathrm{i}}}$

(Equation 8)

where $\mathrm{R}$ is the total relative risk for a dam component over a range of pools

$P_{i}$ is the probabality of the pool event from $i$ to event $n$

$F_{i}$ is the probabality of failure of the component at pool event, $i$

$\mathrm{D}_{\mathrm{i}}$ is the extent of damages from the pool and component failure during pool event, $\mathrm{i}$

$a_{i}$ is the risk consequence factor that relates to the probability of failure during event, $\mathrm{i}$

The inputs for this equation use data that is usually available for most projects such as the stage frequency curves (pool elevation versus probability) and dam- 
age frequency curves from DAMBREAK calculations. The probability of failure for each component can be determined based on the level of risk assessment that is being performed. For pre-screening portfolio assessment levels, the use of expert-opinion elicitation or simple reliability modeling would be sufficient to estimate the probability of failure for most dam components. For more detailed portfolio assessment levels, the results from either engineering reliability models at a level similar to models for major rehabilitation or fragility analysis models or response surface reliability models (nonlinear response under various load conditions than designed) can be utilized. In addition the use of fault trees, failure modes effects and criticality analysis can also be tied in at any level of assessment as well.

A hypothetical example is shown in Table 8 below to estimate gate and foundation risk using the above equation for a spillway system. Table 8 shows the relative effect of using both a risk consequence factor of 1 and a nonlinear value for the risk consequence factor, $\alpha$. This value is based on the nonlinear relationship between the factor and the probability of failure as defined in Figure 10. Based on this nonlinear relationship, the relative risk contribution for the gates is approximately $1.1 \times 10^{14}$ while the risk for the foundation is $2.1 \times 10^{15}$.

Table 8. Hypothetical example of risk from gate or foundation failure for a spillway system. Gates Failure

Alpha $=$

1

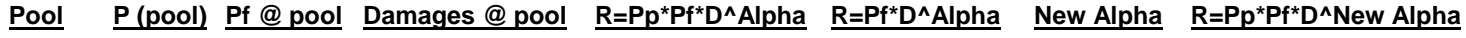

\begin{tabular}{|c|c|c|c|c|c|c|r|}
\hline 5 & 0.99 & 0.0001 & 100000 & 9.90 & 10.00 & 1.000100005 & 9.91140493 \\
\hline 10 & 0.5 & 0.01 & 200000 & 1000.00 & 2000.00 & 1.010050167 & 1130.514761 \\
\hline 15 & 0.2 & 0.1 & 500000 & 10000.00 & 50000.00 & 1.105170918 & 39752.63375 \\
\hline 20 & 0.1 & 0.2 & 1000000 & 20000.00 & 200000.00 & 1.221402758 & 426036.2415 \\
\hline 25 & 0.01 & 0.5 & 2000000 & 10000.00 & 1000000.00 & 1.648721271 & 122352313.5 \\
\hline 30 & 0.001 & 0.9 & 3000000 & 2700.00 & 2700000.00 & 2.459603111 & $7.68051 \mathrm{E}+12$ \\
\hline 35 & 0.0001 & 0.99 & 5000000 & 495.00 & 4950000.00 & 2.691234472 & $1.05714 \mathrm{E}+14$ \\
\hline
\end{tabular}

$44204.9 \quad R=\quad 1.13395 \mathrm{E}+14$

$\begin{array}{lll}\text { Foundation Failure } & \text { Alpha }= & 1\end{array}$

Pool $\quad P($ pool $) \quad P f @$ pool Damages @ pool $\quad R=P p^{\star} P f^{*} D^{\wedge}$ Alpha $\quad R=P f^{\star} D^{\wedge}$ Alpha $\quad$ New Alpha $\quad R=P p^{\star} P f^{*} D^{\wedge}$ New Alpha

\begin{tabular}{|c|r|r|r|r|r|r|r|}
\hline 5 & 0.99 & 0.00001 & 20000 & 1.98 & 2.00 & 1.00001 & 1.980241696 \\
\hline 10 & 0.5 & 0.001 & 50000 & 250.00 & 500.00 & 1.0010005 & 253.3038724 \\
\hline 15 & 0.2 & 0.01 & 70000 & 1400.00 & 7000.00 & 1.010050167 & 1602.773848 \\
\hline 20 & 0.1 & 0.1 & 2000000 & 20000.00 & 200000.00 & 1.105170918 & 91984.59597 \\
\hline 25 & 0.01 & 0.5 & 4000000 & 20000.00 & 2000000.00 & 1.648721271 & 383642526.6 \\
\hline 30 & 0.001 & 0.9 & 700000 & 6300.00 & 6300000.00 & 2.459603111 & $6.17258 \mathrm{E}+13$ \\
\hline 35 & 0.0001 & 0.99 & 15000000 & 1485.00 & 14850000.00 & 2.691234472 & $2.0332 \mathrm{E}+15$ \\
\hline
\end{tabular}




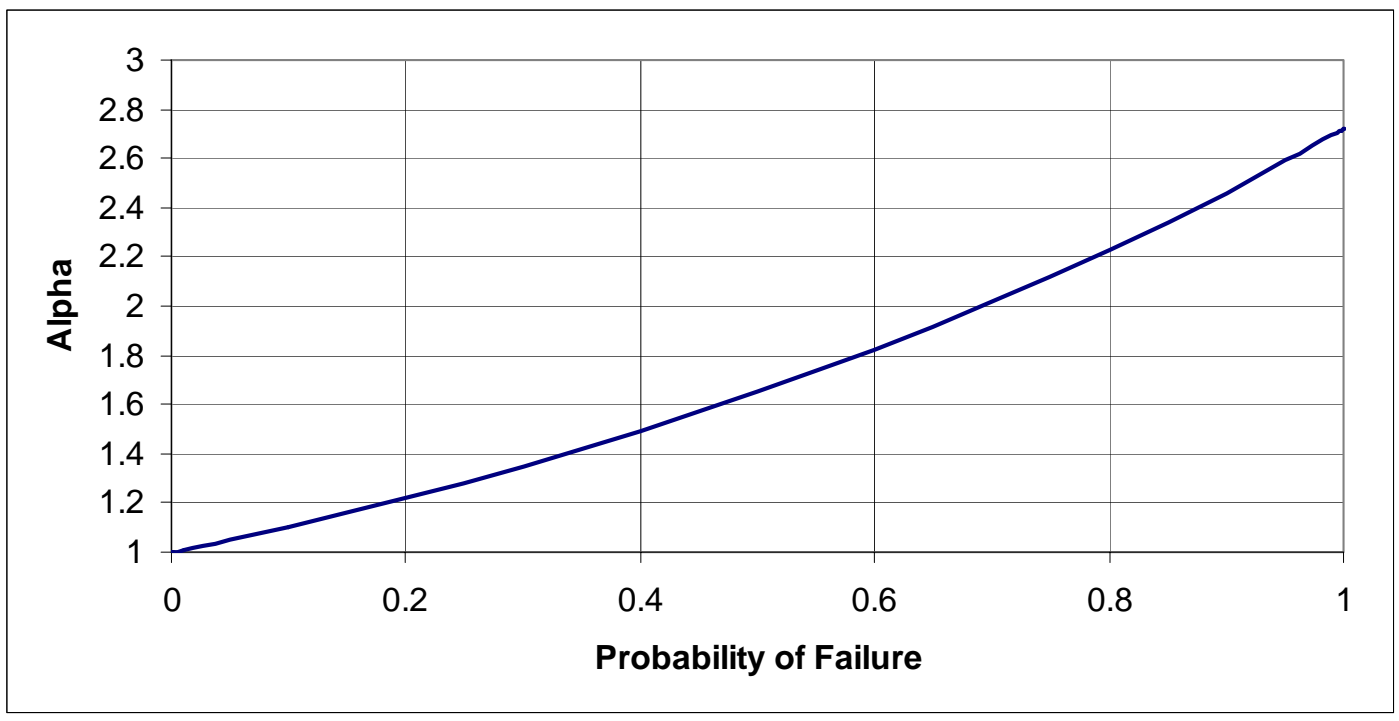

Figure 10. Nonlinear relationship between risk consequence factor and probability of failure.

The time-dependency aspects of the components or the hazard rates also can be used in a similar analysis. The component reliability could be either time- or event-dependent if the component degrades or is subject to another event that is not hydraulically related. Equation 8 can be modified to address dam risk by incorporating the time aspects of the probabilities of failure for various dam components as follows:

$R(t)=\stackrel{̊}{\mathrm{a}}_{0}^{t} \underset{\mathrm{i}}{\stackrel{\mathrm{n}}{\mathrm{a}}} P_{\mathrm{i}} F_{\mathrm{i}}(t) D_{\mathrm{i}}^{a_{\mathrm{i}}}(t)$

Equation 9

where $\mathrm{R}(\mathrm{t})$ is the total relative risk over time for a dam component over a range of pools

$P_{i}$ is the probabality of the pool event from $i$ to event $n$

$F_{i}(t)$ is the time-dependent probabality of failure of the component at pool event, $i$

$D_{i}(t)$ is the time-dependent extent of damages from the pool and component failure during pool event, $i$ $a_{i}$ is the risk consequence factor that relates to the probability of failure during event, $\mathrm{i}$

A hypothetical example for the relative risks associated with a gate system consisting of structural, mechanical, and electrical components is shown in Figure 2 (Chapter 2). These relative risk values are calculated using the nonlinear value for the risk consequence factor, $\alpha$, defined in Figure 10. The baseline condition is the time-dependent relative risk without rehabilitation of any components at the spillway project, as shown in Figure 11. Risk-reduction measures or alternatives can also be determined very easily using this method. The alternative risk solutions are presented for (1) the rehabilitation of all the components at a 25 -year cycle and (2) the rehabilitation of the mechanical equipment at 15-year cycle and the structural components at 30-year cycle. These risk curves are shown in 
Figure 12 and Figure 13, respectively, and the overall graph of the alternatives is shown in Figure 14.

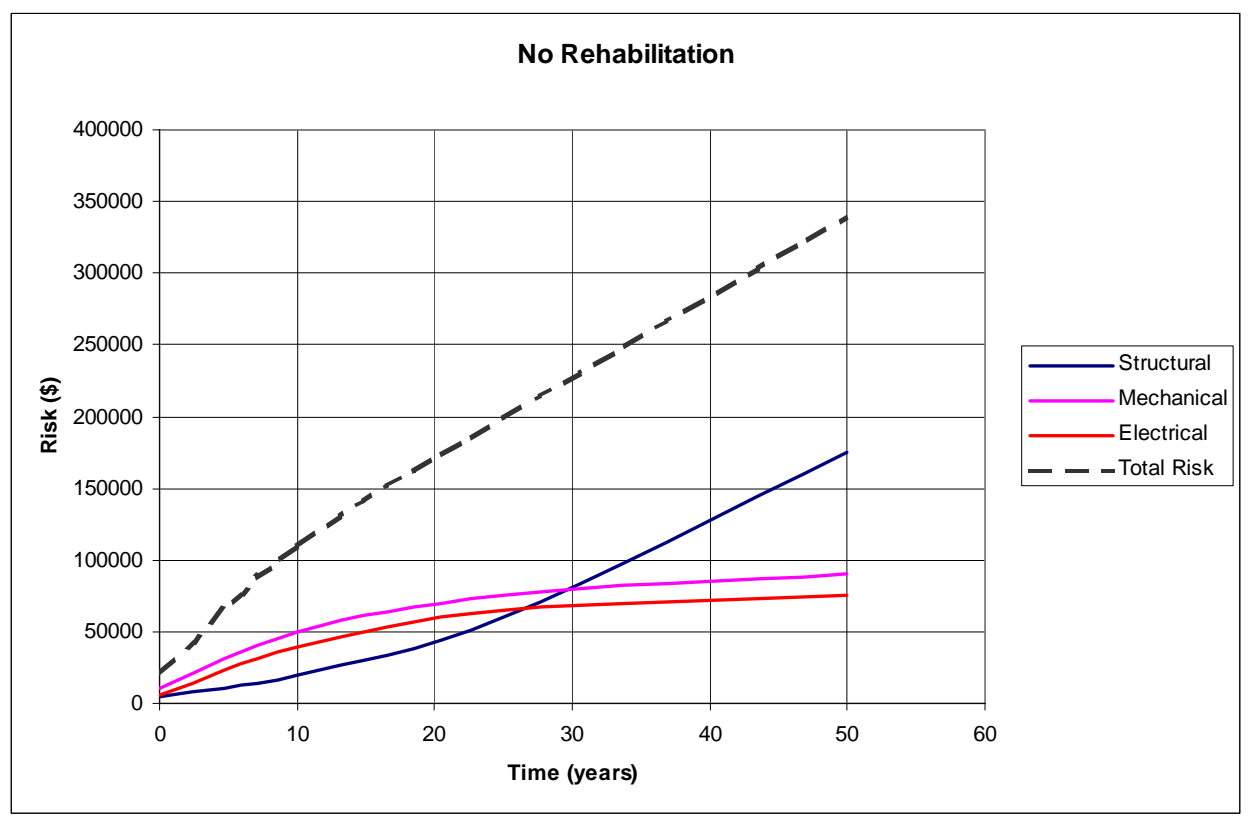

Figure 11. Baseline condition - no rehabilitation.

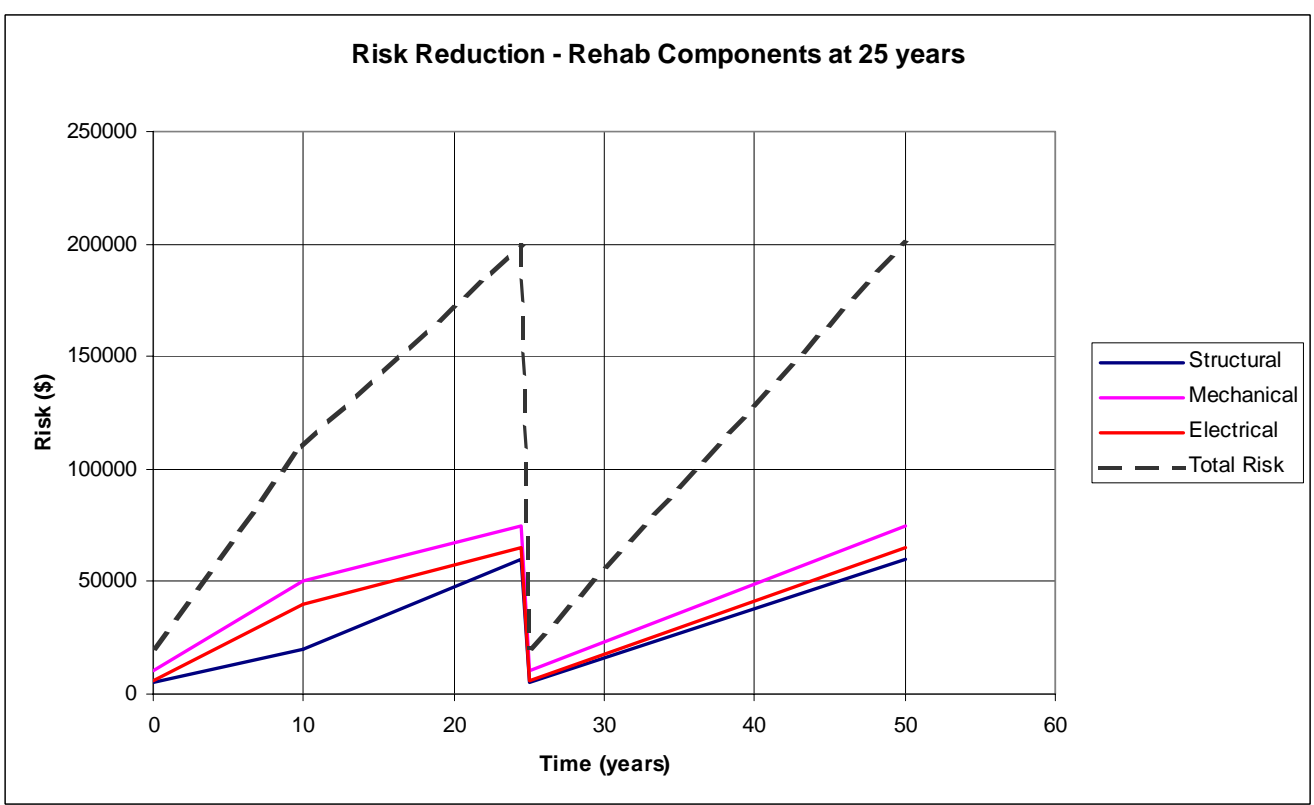

Figure 12. Alternative 1 - rehabilitation of all components in Year 25. 


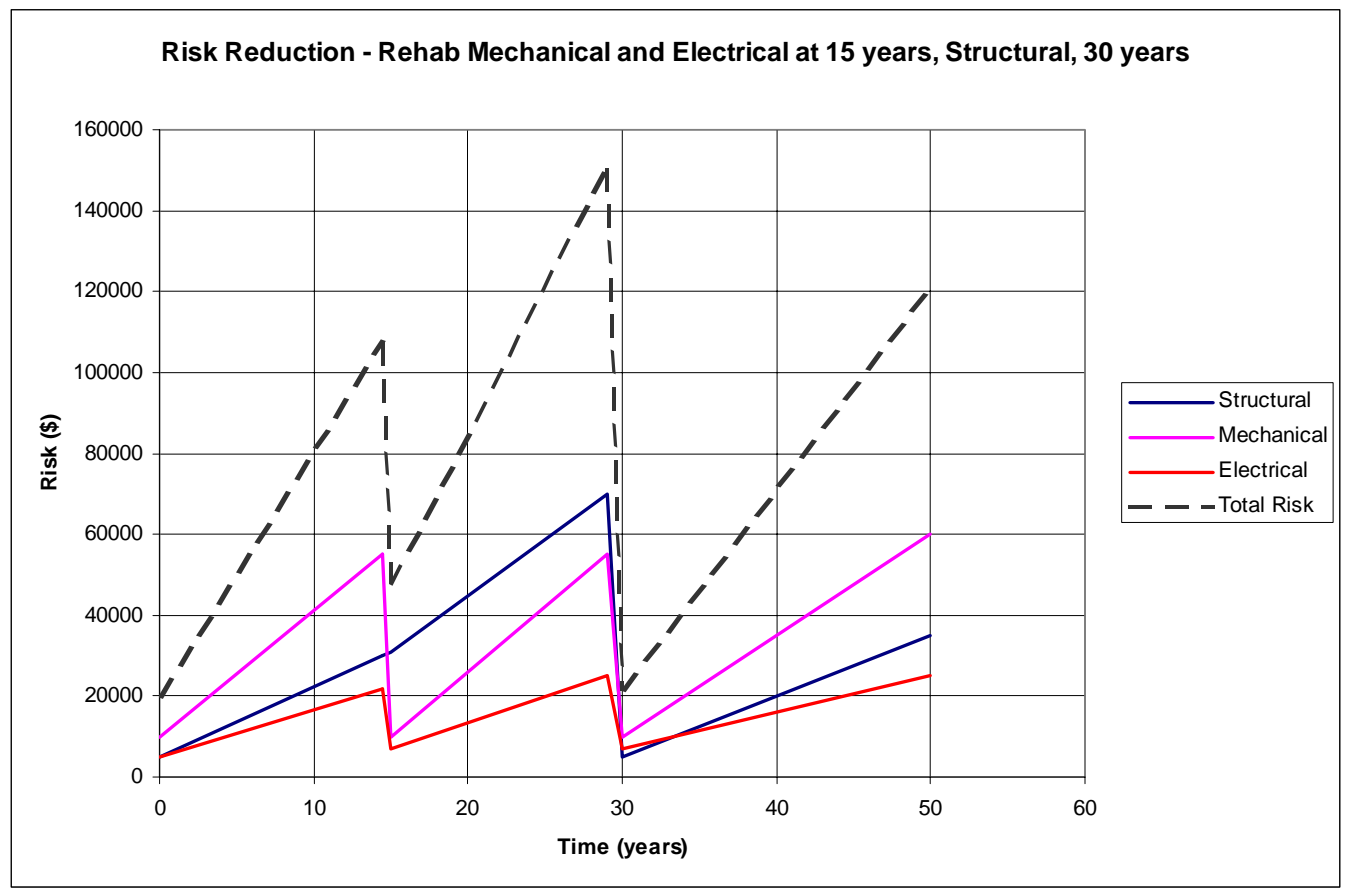

Figure 13. Alternative 2 - rehabilitation of mechanical and electrical components in Year 15 and structural components in Year 30.

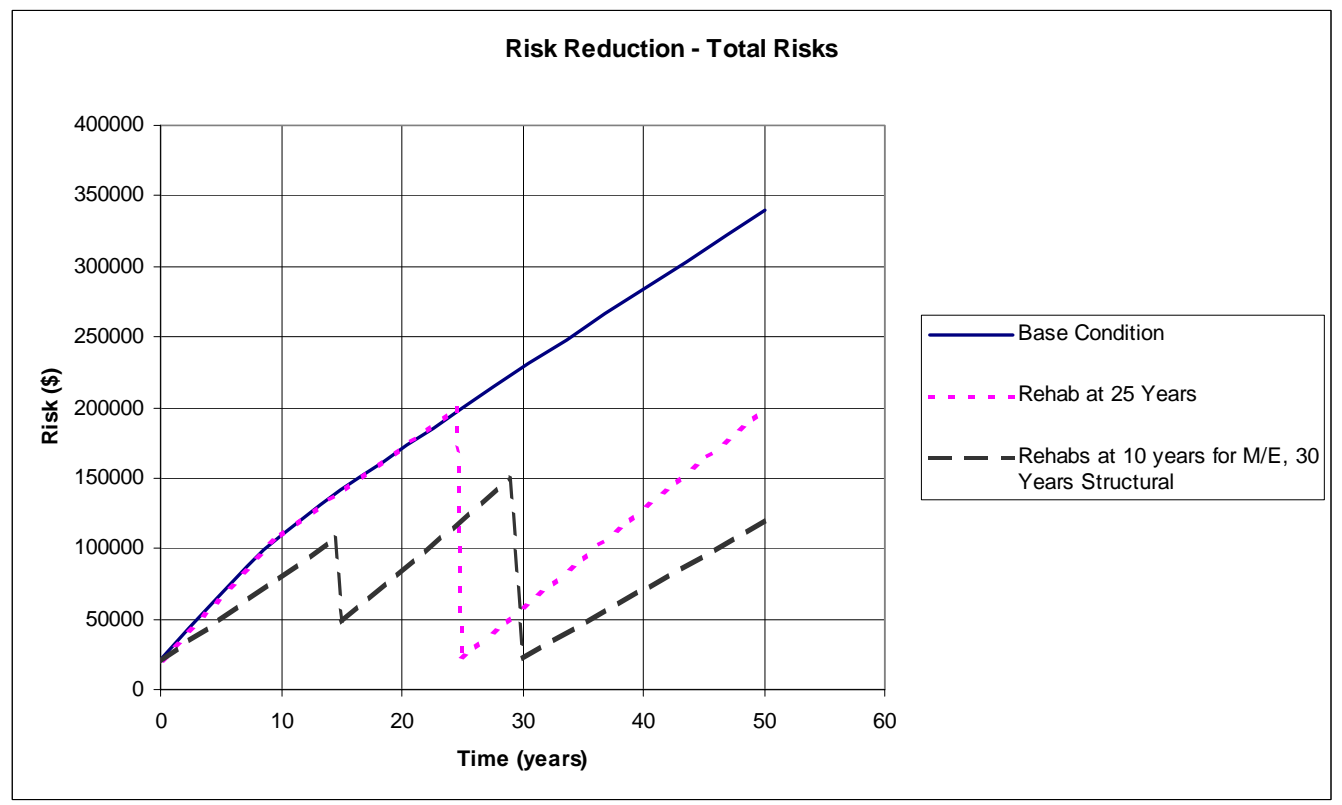

Figure 14. Summary of risk-reduction measures for spillway system.

The use of this time-dependent procedure for risk calculations will permit the development of hazard functions for risk that can be used in the economic calculations of benefit/cost ratio. The damages associated with the risks could include downstream flood damage costs, dam repair costs, emergency action costs, environmental costs, security costs, and potential loss of life. An optimized solution can be determined that coordinates current and future budgets with available 
funding and the priorities of the structures while also conforming to Office of Management and Budget requirements for using benefit/cost ratio in funding proposals (much as it is done in the major rehabilitation process). Another advantage of this method is it presents an equal priority ranking of all dam components over time, including structural, geotechnical, mechanical, and electrical, as well as incorporating site hydrology information and vulnerability risks. 


\section{Conclusions}

Two different criticality methodologies have been presented to assist with the risk analysis of dam gates. These methods can be very useful for practicing engineers. They assist with defining the fault trees associated with dam gates and risk identified for dam gates. Detailed fault trees are also presented for the case of dam spillway system failure in general and gate failure in particular. These fault trees were developed on the basis of technical consultations with Corps engineering, operations, and dam safety personnel.

The first method presented is based on the concept of criticality index and failure modes and effects analysis (FMEA). This method is considered a valuable tool for prescreening of gate subsystems because it accounts for all component failure modes and incorporates the critical nature for each failure mode. This method may also be used to provide a relative ranking of the subsystems of dam gates, which can be used to make important economic decisions such as rehabilitation versus modification of dam gates.

The second method proposes the ranking of failure modes based on a mission criticality to determine the probability of failure for a gate system or subsystem. This method is well suited to assist with making economic decisions if there is ever a need to rehabilitate the dam gates. Proposed future work would include a direct application of the methods to an existing dam gate system. Such a demonstration would promote additional enhancements to the procedures developed here.

The method of Lafitte (1993) is proposed as a potential method for overall risk assessment of spillways because of its compatibility with fault tree analysis to obtain the failure probability. The Lafitte method also provides another advantage: it includes a simple relation for using probability of failure values in its risk calculation. Additional research is recommended to better determine the risk consequence factor, $\alpha$, used in the Lafitte equation for calculating overall risk. 


\section{References}

Boeing System Safety Operating Instruction (1998), "Failure Mode Effects Analyses (FMEA) and Critical Items Lists (CIL)," Huntington Beach, CA.

Ebeling, C.E. (1997), An Introduction to Reliability and Maintainability Engineering, McGraw-Hill Company, New York.

Failure Mode/Mechanism Distributions (1991), Reliability Analysis Center, Rome, N.Y.

Gruetter, F., and Schnitter, N.J. (1982), “Analytical Risk for Assessment for Dams,” Transactions$14^{\text {th }}$ International Congress on Large Dams, Rio de Janeiro, Brazil.

Lafitte, R. (1993), "Probabilistic Risk Analysis of Large Dams: Its Value and Limits" International Water Power \& Dam Construction, Volume 45, No. 3, March.

Lafitte, R. (1996), "Classes of Risk for Dams," International Journal on Hydropower and Dams, Volume 3, No. 6.

Locks, M. O. (1995), Reliability, Maintainability, and Availability Assessment, Second Edition, ASQC Quality Press, Milwaukee, Wisconsin.

MIL-STD-1629A (1980), Procedures for Performing a Failure Mode, Effects and Criticality Analysis, Naval Publications and Forms Center, Philadelphia.

MIL-HDBK-217F (1991), Reliability Prediction of Electronic Equipment Rome Air Development Center, Griffiss Air Force Base, New York.

Putcha, C.S., and Patev, R.C. (2000), Investigation of Risk Assessment Methodology for Dam Gates and Associated Operating Equipment, ERDC/ITL TR-00-3, Engineer Research and Development Center, U.S. Army Corps of Engineers.

Putcha, C.S., Ryan, K.E., Stell, R., Kimura, T., Podgorski, R.R., Ai, T., McCormick, B.D., Tate, G.T., Stenger-Nguyen, P., Peercy, R., Coursen, J.T., and Daniels, F.V., (2001), "Relation Between Criticality of Failure Mode and Criticality Index for Engineering Systems", Proceedings of the $18^{\text {th }}$ Canadian Congress of Applied Mechanics, Memorial University of Newfoundland, St. John's, Canada, June $3-7$.

Walpole, R.E., and Myers, R.H. (1993), Probability and Statistics for Engineers and Scientists, McMillan Publishing Company. 
Public reporting burden for this collection of information is estimated to average 1 hour per response, including the time for reviewing instructions, searching existing data sources, gathering and maintaining the data needed, and completing and reviewing this collection of information. Send comments regarding this burden estimate or any other aspect of this collection of information, including suggestions for reducing this burden to Department of Defense, Washington Headquarters Services, Directorate for Information Operations and Reports (0704-0188), 1215 Jefferson Davis Highway, Suite 1204, Arlington, VA 22202-4302. Respondents should be aware that notwithstanding any other provision of law, no person shall be subject to any penalty for failing to Davis Highway, Suite 1204, Arlington, VA 22202-4302. Respondents should be aware that notwithstanding any other provision of law, no person shall be subject to any pen with a collection of information if it does not display a currently valid OMB control number. PLEASE DO NOT RETURN YOUR FORM TO THE ABOVE ADDRESS.
comply w

\section{REPORT DATE (DD-MM-YYYY) $05-2005$ 2. REPORT TYPE Final}

4. TITLE AND SUBTITLE

Methodology for Risk Analysis of Dam Gates and Associated Operating Equipment Using Fault Tree Analysis

3. DATES COVERED (From - To)

5a. CONTRACT NUMBER

5b. GRANT NUMBER

5c. PROGRAM ELEMENT NUMBER

5d. PROJECT NUMBER

6. AUTHOR(S)

Robert C. Patev, Chandra Putcha, and Stuart D. Foltz

5e. TASK NUMBER

5f. WORK UNIT NUMBER

33262

8. PERFORMING ORGANIZATION REPORT NUMBER

7. PERFORMING ORGANIZATION NAME(S) AND ADDRESS(ES)

U.S. Army Engineer Research and Development Center (ERDC)

Construction Engineering Research Laboratory (CERL)

ERDC TR-05-3

PO Box 9005

Champaign, IL 61826-9005

\section{SPONSORING I MONITORING AGENCY NAME(S) AND ADDRESS(ES)}

HQ USACE

$441 \mathrm{G}$ Street

Washington, DC 20314-1000

11. SPONSOR/MONITOR'S REPORT NUMBER(S)

\section{DISTRIBUTION / AVAILABILITY STATEMENT}

Approved for public release; distribution is unlimited.

\section{SUPPLEMENTARY NOTES}

\section{ABSTRACT}

With limited maintenance dedicated to aging dam spillway gate structures, there is an increased risk of gate inoperability and corresponding dam failure due to malfunction or inadequate design. This report summarizes research on methodologies to assist in quantifying risks related to dam gates and associated operating equipment, and how those risks relate to overall spillway failure risk. The objective of the research was to demonstrate how fault tree analytical methods may be applied to improve the quality of dam gate risk analysis.

Two different methods of prescreening analysis are presented and evaluated. The first uses probabilities for more events, defined more precisely than in standard practice, and adds criticality ranking; the second uses more traditional estimation of failure probabilities in conjunction with subsystem importance-ranking factors to estimate overall gate system failure probability. Both methods can be linked qualitatively with the Lafitte risk method through event costs and consequences to determine the overall risk for a dam spillway system.

Enhancement of the two demonstrated methods would require a direct application of the methods to an existing dam gate system. Also, additional research would be necessary to better determine the risk consequence factor, $\alpha$, used in the Lafitte equation for calculating overall risk.

\section{SUBJECT TERMS}

hydraulic structures, hydraulic gates, dams, risk assessment, civil works

\begin{tabular}{|c|c|c|c|c|c|}
\hline \multicolumn{3}{|c|}{ 16. SECURITY CLASSIFICATION OF: } & \multirow{2}{*}{$\begin{array}{l}\text { 17. LIMITATION } \\
\text { OF ABSTRACT }\end{array}$} & \multirow{2}{*}{$\begin{array}{l}\text { 18. NUMBER } \\
\text { OF PAGES }\end{array}$} & 19a. NAME OF RESPONSIBLE PERSON \\
\hline $\begin{array}{l}\text { a. REPORT } \\
\text { Unclassified }\end{array}$ & $\begin{array}{l}\text { b. ABSTRACT } \\
\text { Unclassified }\end{array}$ & $\begin{array}{l}\text { c. THIS PAGE } \\
\text { Unclassified }\end{array}$ & & & $\begin{array}{l}\text { 19b. TELEPHONE NUMBER (in- } \\
\text { clude area code) }\end{array}$ \\
\hline NSN 7 & & & & & $\begin{array}{l}\text { Standard Form } 298 \text { (Rev. 8-98) } \\
\text { Prescribed by ANSI Std. 239.18 }\end{array}$ \\
\hline
\end{tabular}

